\title{
Descriptive characteristics of continuous oximetry measurement in moderate to severe COVID-19 patients
}

\author{
Jonathan A. Sobel ${ }^{1}$, Jeremy Levy ${ }^{1,2}$, Ronit Almog ${ }^{3}$, Anat Reiner-Benaim ${ }^{4}$, Asaf Miller ${ }^{3}$, Danny Eytan ${ }^{3}$, and Joachim A. \\ Behar $^{1, \square}$ \\ ${ }^{1}$ Faculty of Biomedical Engineering, Technion, Israel Institute of Technology, Haifa, Israel \\ ${ }^{2}$ Faculty of Electrical Engineering, Technion, Israel Institute of Technology, Haifa, Israel \\ ${ }^{3}$ Rambam Health Care Campus, Haifa, Israel \\ ${ }^{4}$ School of Public Health, Faculty of Health Sciences, Ben Gurion University of the Negev, Be'er Sheva, Israel
}

\begin{abstract}
Non-invasive oxygen saturation (SpO2) is a central vital sign that supports the management of COVID-19 patients. However, reports on $\mathrm{SpO} 2$ characteristics are scarce and none has analysed high resolution continuous SpO2 in COVID-19. We provide the first analysis of high resolution $\mathrm{SpO2}$ across the spectrum of COVID-19 disease severity and respiratory support. A total of $367 \mathrm{COVID-19}$ patients' recordings, comprising 27K hours of continuous SpO2 data, could be retrieved from patients hospitalized at the Rambam Health Care Campus. Using oximetry digital biomarkers (OBM), we quantified $\mathrm{SpO} 2$ characteristics and showed that the percentage of time under $93 \%$ oxygen saturation threshold is the best single OBM discriminating between critical and non-critical patients. OBMs traditionally used in the field of sleep medicine research, were informative for assessing the patient's response to respiratory support. In addition, periodicity and hypoxic burden biomarkers were affected up to several hours before the initiation of the mechanical ventilation. Characteristics from high resolution $\mathrm{SpO} 2$ signal may enable to anticipate clinically relevant events, monitoring of treatment response and may be indicative of future deterioration.
\end{abstract}

COVID-19 | Pulse oximetry | Continuous monitoring | Intensive care Correspondence: jbehar@technion.ac.il

\section{Introduction}

The ongoing coronavirus disease 2019 (COVID-19) pandemic has spread all over the world and caused, as of early August 2021, over 4,3 million deaths. Approximately 15$20 \%$ of confirmed cases develop severe disease, while the fatality rate is $2-5 \%^{1-3}$ depending on the country and the monitored period.

In hospitalized patients with acute respiratory infections, such as patients with COVID-19, continuous SpO2 monitoring has become central and is used to detect desaturation events required for patient triage, risk stratification and escalation of treatment, and to allow the clinicians to track the response to therapeutic interventions such as oxygen enrichment or ventilation ${ }^{4,5}$. Specifically in COVID-19 patients, $\mathrm{SpO} 2$ is often used in the ROX score (ratio of SpO2/FIO2 to respiratory rate) or in the $\mathrm{SpO} 2 / \mathrm{FiO} 2$ ratio to predict the future need for oxygen support or mechanical ventilatory support and the success of a therapy ${ }^{6-8}$. Nevertheless, these studies rely mostly on admission data or discrete measurements during hospitalization. To our knowledge, no study investigated continuous high resolution $\mathrm{SpO} 2$ characteristics (patterns and dynamics) in COVID-19 patients.
The present work aims to describe high resolution $\mathrm{SpO} 2$ signal characteristics and potential usage along the treatment course for non-critical, critical with or without oxygen support and critical mechanically ventilated patients. The specific objectives of this work are: (1) Determining global $\mathrm{SpO} 2$ signal characteristics correlated with disease severity and/or the level of respiratory support; (2) Investigating the optimal definition of a relative or absolute threshold for defining clinically relevant desaturations; (3) Defining characteristics of the $\mathrm{SpO} 2$ signal including desaturation parameters and oximetry derived digital biomarkers (OBMs) allowing for the differentiation between critical and non-critical groups or those affected by the level of support; (4) highlighting the potential of OBMs extracted from high resolution $\mathrm{SpO} 2$ signal for the detection of early signs of deterioration leading to the indication of mechanical ventilation and for tracking patient's response to medical treatment.

\section{Results}

Severe COVID-19 patients and hospitalisation course. Patients were split into two groups based on disease severity with 162 critical and 205 non-critical patients (Table 1). Male patients were prevalent in both groups $(60,5 \%$ in the non-critical group and $72,8 \%$ in the critical group). The in-hospital mortality was $38,9 \%$ in the critical group. The age distribution was significantly different ( $\mathrm{p}$-value $<0,05$ ) with more patients 65-74 years old in the critical group and less patients 18-44 years old with respect to the non-critical group. The BMI distribution was balanced between groups. The length of stay (Table S1, Figure S3) was significantly longer in the critical group ( $\mathrm{p}$-value $<0,001$, median noncritical $=5$ days, median critical $=14$ days). Patients in the critical groups had significantly more overall comorbidities (p-value $=0,01$, Table 1, Table S2). Regarding vital signs at admission (Table $\mathrm{S} 1$ ), critical patients depicted a lower room saturation ( $\mathrm{SpO} 2$ measured breathing room air) and oxygen saturation ( $\mathrm{SpO} 2$ measured under oxygen support). The respiratory rate was significantly higher in the critical group indicating tachypnea.

Qualitative analysis of SpO2 characteristics. A typical hospital course of a patient after admission is represented in Figure 1A. Hospitalized patients are monitored in the ward or in ICU. Qualitatively, the continuous monitoring of $\mathrm{SpO} 2$ NOTE: This preprint reports new research that has not been certified by peer review and should not be used to guide clinical practice. 


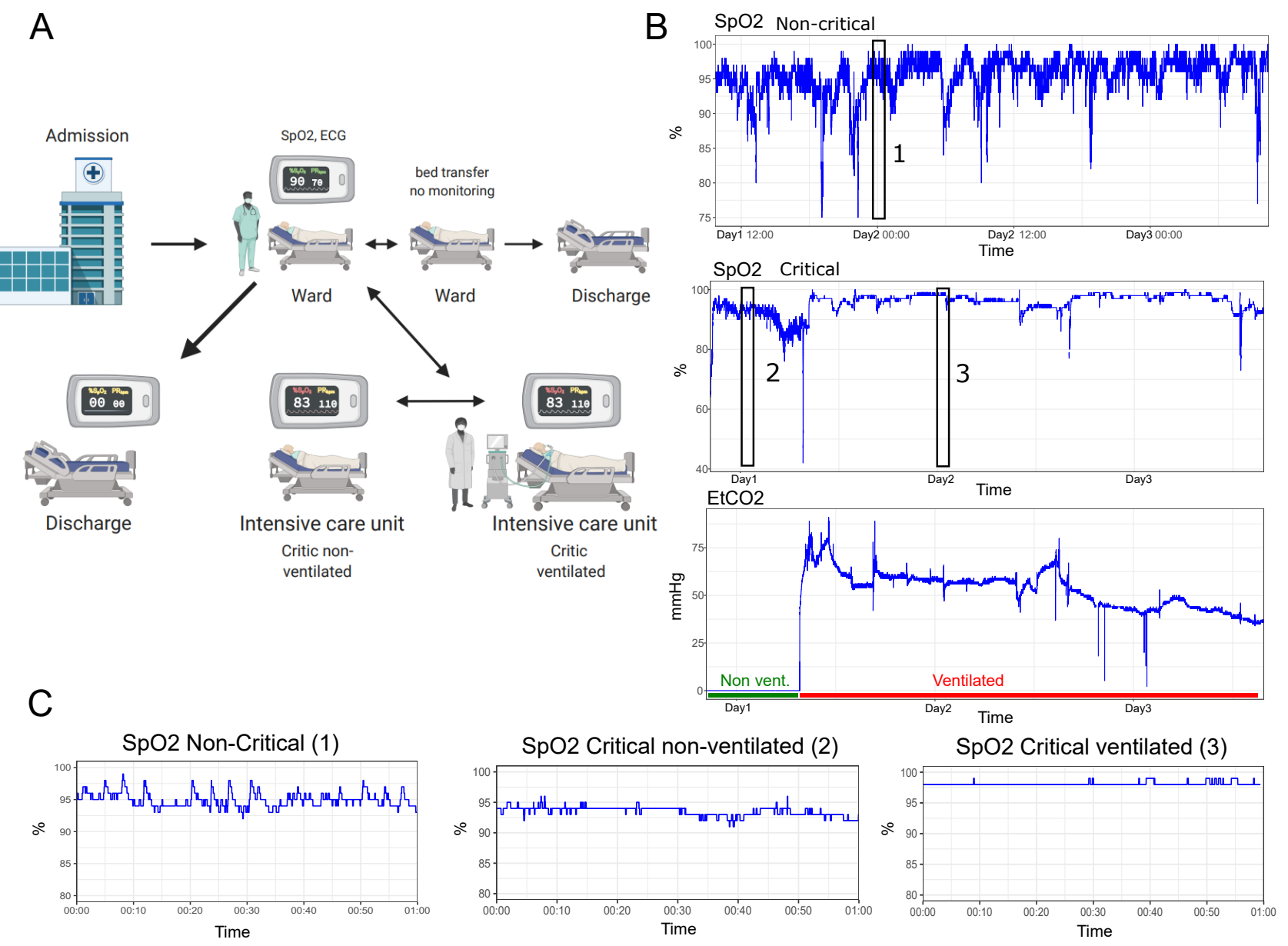

Figure 1. Patient in-hospital movement and examples of SpO2 signal in critical and non-critical cases. A) Frequent in-hospital movement of ward monitored patients. For non-severe patients monitoring is only performed part time and a patient might be transferred or discharged depending on his health status. B) SpO2 and EtCO2 signals of a non-critical and a critical COVID-19 patient with an initiation of ventilation. The transition between non-ventilated and ventilated state is clearly visible after an event of intense desaturation. Non-mechanically ventilated area is indicated in green and mechanically ventilated area is indicated in red. On the EtCO2 channel C) SpO2 signal of the same patients zoomed in on $1 \mathrm{~h}$ intervals, highlighted by black rectangles in panel $\mathrm{B}$.

Table 1. Population sample characteristics. Abbreviation: BMI body mass index

\begin{tabular}{|c|c|c|c|c|c|c|}
\hline variable & & non-critical & & critical & & FDR adjusted p-value \\
\hline & & $(\mathrm{n}=205)$ & & $(\mathrm{n}=162)$ & & \\
\hline \multirow[t]{2}{*}{ gender } & Male & 124 & $(60,5 \%)$ & 118 & $(72,8 \%)$ & 0,07 \\
\hline & Female & 81 & $(39,5 \%)$ & 44 & $(27,2 \%)$ & \\
\hline \multirow{2}{*}{ in-hospital mortality } & FALSE & 205 & $(100 \%)$ & 99 & $(61,1 \%)$ & $6,40 \mathrm{e}-21$ \\
\hline & TRUE & 0 & $(0 \%)$ & 63 & $(38,9 \%)$ & \\
\hline \multirow[t]{5}{*}{ age group } & $18-44$ & 28 & $(13,7 \%)$ & 8 & $(4,9 \%)$ & 0,02 \\
\hline & $45-54$ & 24 & $(11,7 \%)$ & 28 & $(17,3 \%)$ & \\
\hline & $55-64$ & 51 & $(24,9 \%)$ & 28 & $(17,3 \%)$ & \\
\hline & $65-74$ & 35 & $(17,1 \%)$ & 44 & $(27,2 \%)$ & \\
\hline & $75+$ & 67 & $(32,7 \%)$ & 54 & $(33,3 \%)$ & \\
\hline \multirow[t]{4}{*}{ BMI group } & $<=20$ & 4 & $(2,1 \%)$ & 2 & $(1,3 \%)$ & 0,74 \\
\hline & $20-25$ & 42 & $(21,6 \%)$ & 27 & $(17,2 \%)$ & \\
\hline & $25-30$ & 69 & $(35,6 \%)$ & 57 & $(36,3 \%)$ & \\
\hline & $30<$ & 79 & $(40,7 \%)$ & 71 & $(45,2 \%)$ & \\
\hline \multirow[t]{2}{*}{ comorbidity } & FALSE & 67 & $(32,7 \%)$ & 29 & $(17,9 \%)$ & 0,01 \\
\hline & TRUE & 138 & $(67,3 \%)$ & 133 & $(82,1 \%)$ & \\
\hline
\end{tabular}




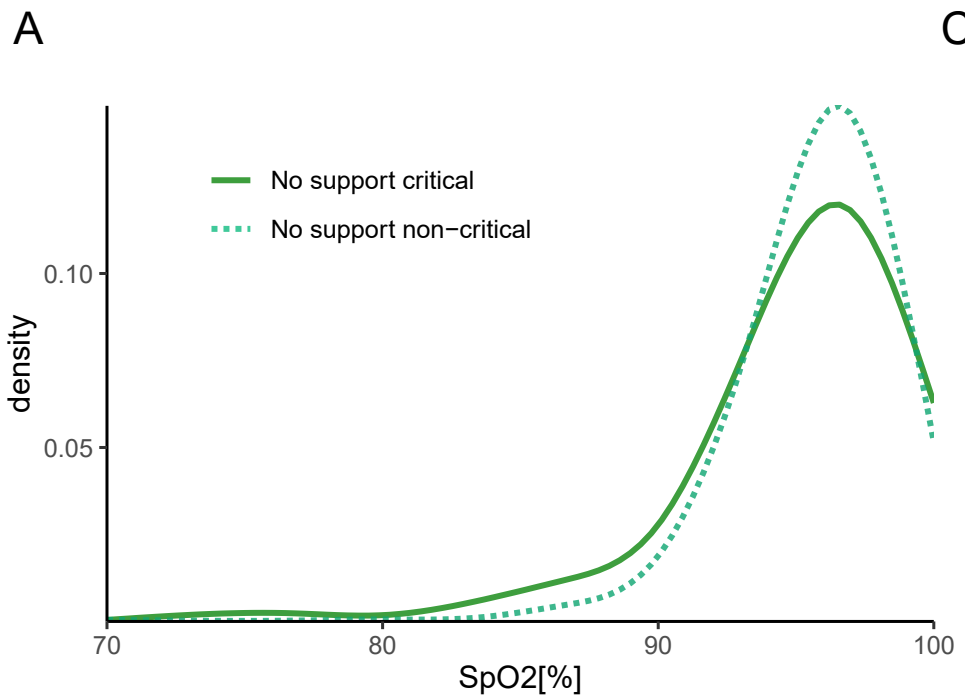

B
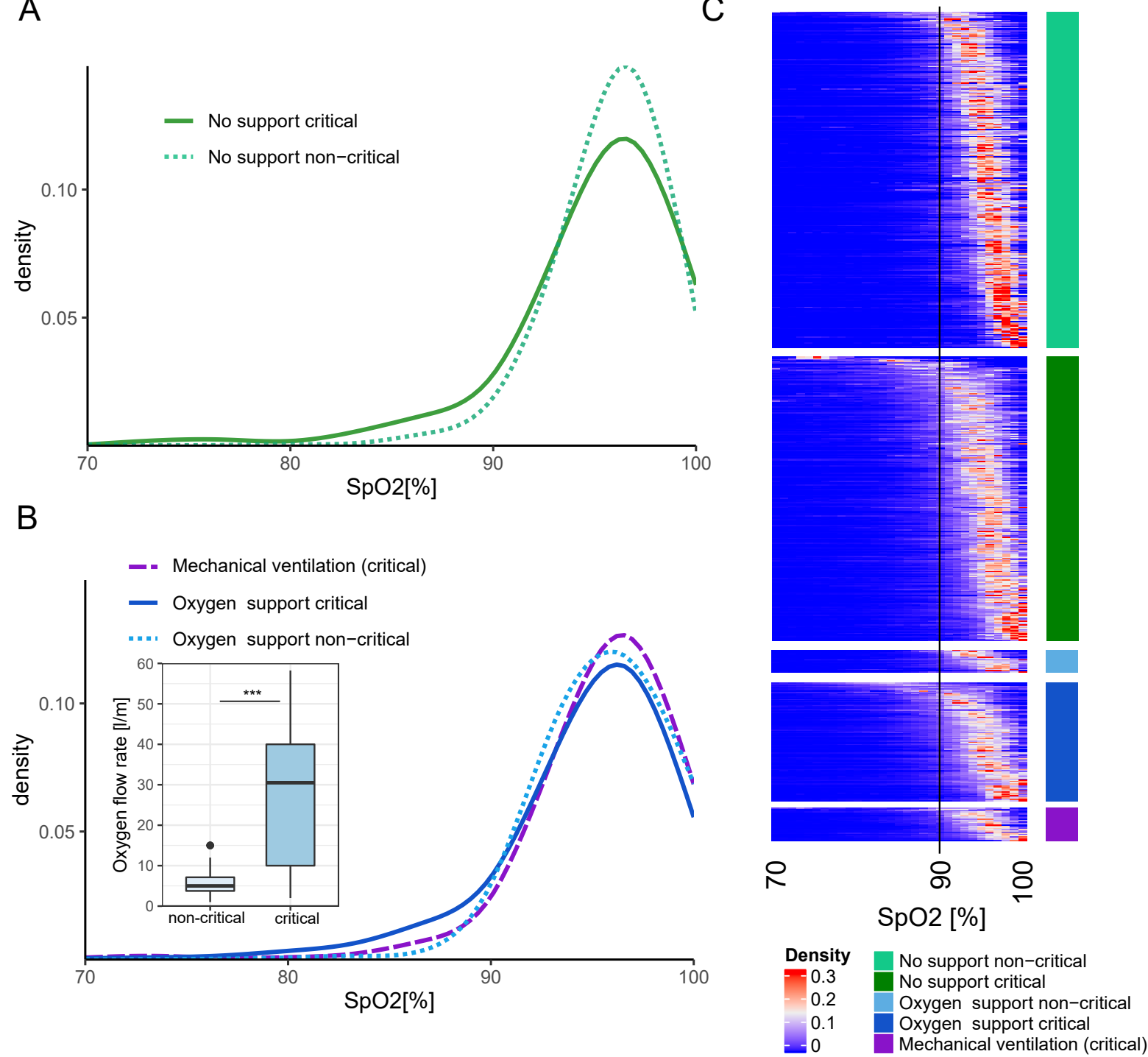

Figure 2. Global characteristics of SpO2 signal. A) Density distribution of SpO2 for non-critical and critical patients without support. B) Density distribution of SpO2 from noncritical and critical patients for intervals under oxygen support or mechanical ventilation. The level of oxygen support (oxygen flow rate) was compared between non-critical and critical patients. The center of boxplot indicates the median, and the bottom and top edges indicate the 25th and 75th percentiles, points indicates outliers. C) SpO2 density heatmap for each interval of SpO2 signal of patient in each group. A vertical black line represent the threshold of $90 \% \mathrm{SpO} 2$ recommended in the WHO guidelines ${ }^{5}$ to identify severe patients.

of a single patient depicted frequent small desaturations in a non-critical case, while a critical patient presented prolonged events of low SpO2 (Figure 1B). The initiation of mechanical ventilation was visible on the EtCO2 channel. The dynamics of the $\mathrm{SpO} 2$ signal was noticeably impacted by mechanical ventilation, with a higher $\mathrm{SpO} 2$ level and reduced variability (Figure 1C).

\section{Quantitative analysis of SpO2 characteristics.}

SpO2 distribution.. The mean SpO2 was significantly lower among critical patients without support, compared to the noncritical group ( $\mathrm{p}$-value $<0,05,2 \mathrm{~A}, \mathrm{C}$ ). The lower $\mathrm{SpO} 2$ range between $80 \%$ and $90 \%$ depicted a higher density in the critical group ( $\mathrm{p}$-value $<0,01$ ). The non-critical group showed a narrower peak of densities centered around 96\% SpO2. A similar, although milder trend was observed in the critical group versus non-critical patients by oxygen delivery devices (Figure 2B,C). The median oxygen flow rate used for the oxygen support was significantly higher in critical patients ( $\mathrm{p}$-value $<0,001$ ). The use of mechanical ventilation reduced the density of low $\mathrm{SpO} 2(80 \%-90 \%)$ to a level closer to that seen in non-critical patients. On the other hand, critically ill patients who were mechanically ventilated or on oxygen support depicted a higher density of SpO2 level between $97 \%$ and $100 \%$ compared to critical non ventilated and non- 
medRxiv preprint doi: https://doi.org/10.1101/2021.09.26.21264135; this version posted November 8, 2021. The copyright holder for this preprint (which was not certified by peer review) is the author/funder, who has granted medRxiv a license to display the preprint in perpetuity.

It is made available under a CC-BY-ND 4.0 International license .

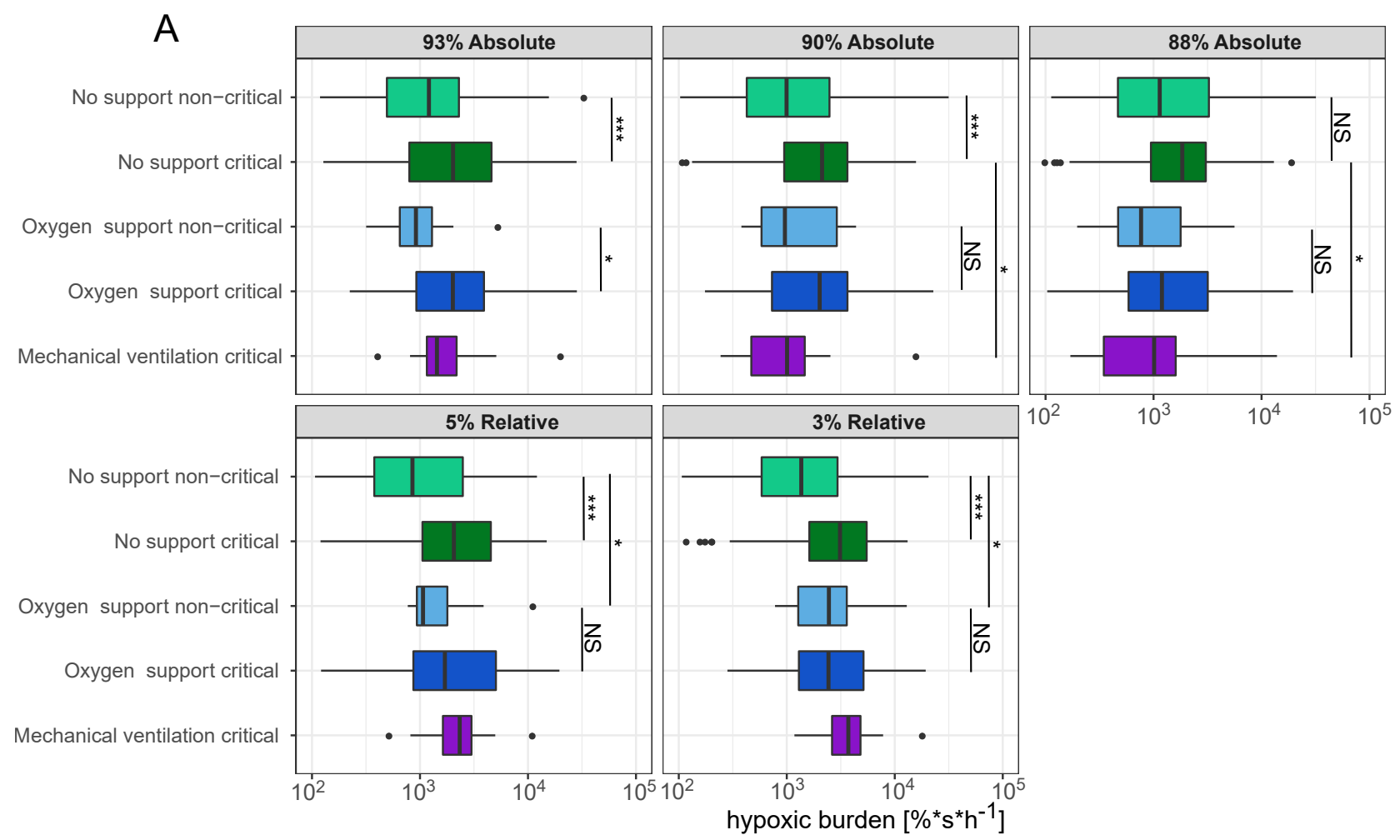

B
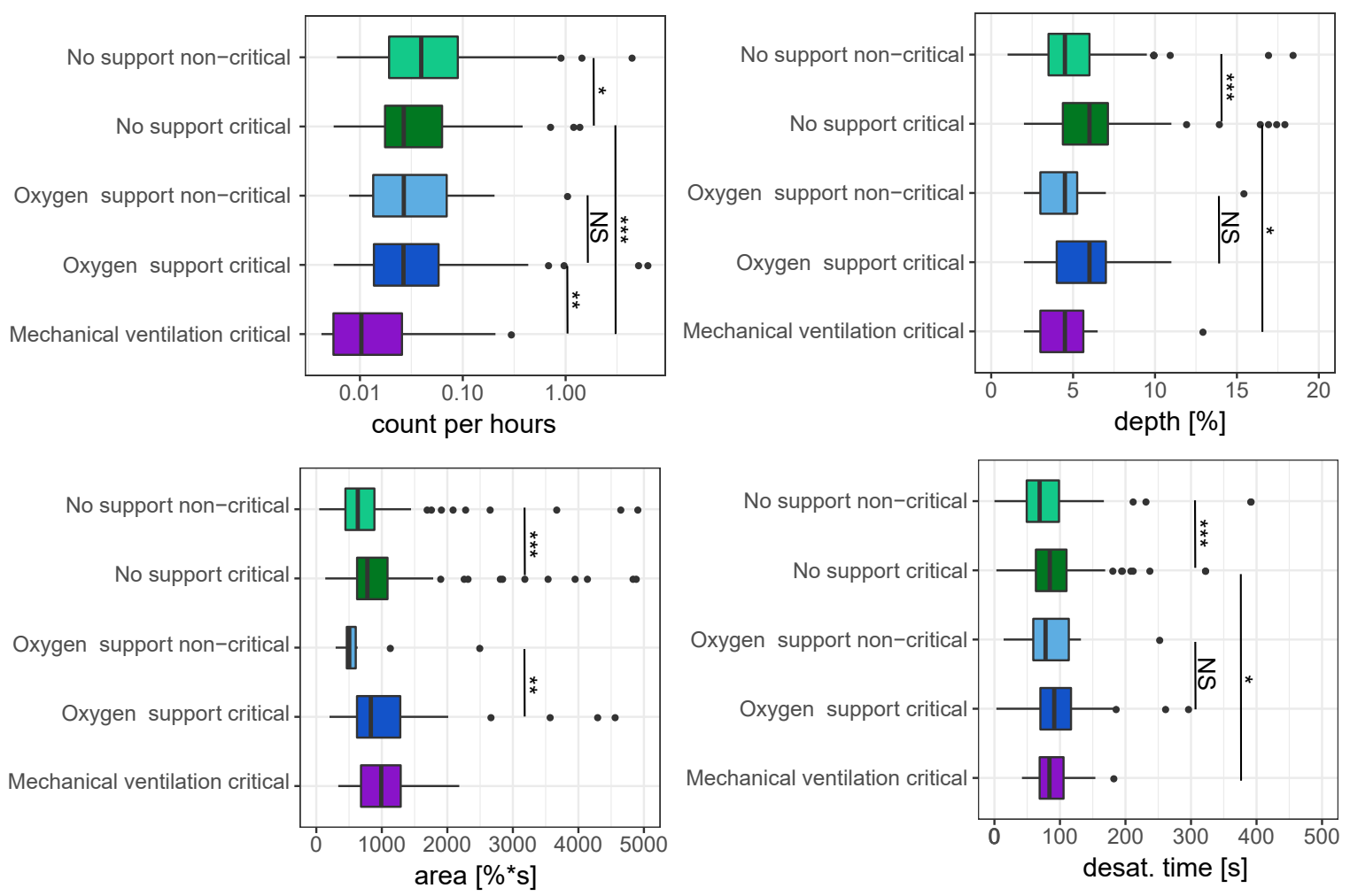

Figure 3. Desaturation definition and parameters A) Hypoxic burden for each relative or absolute desaturation definition. The hypoxic burden was defined as the sum of desaturation areas normalised by recording duration. The hypoxic burden was based on relative or absolute threshold and was measured under oxygen support, mechanical ventilation or without support in critical and non-critical patients. B) Desaturation characteristics for critical and non-critical patients with or without oxygen or mechanical support. The results are shown for an absolute desaturation threshold of $93 \%$. The number of desaturation per hour, the depth the area and the desaturation time (duration between the beginning and the minimum) are represented for each group. ${ }^{* * *}$ Wilcoxon test $p$-value $<0,001,{ }^{* *} p$-value $<0,01,{ }^{*} p$-value $<0,05$, NS non-significant. The center of boxplot indicates the median, and the low and high edges indicate the 25th and 75th percentiles, points indicates outliers. 
A

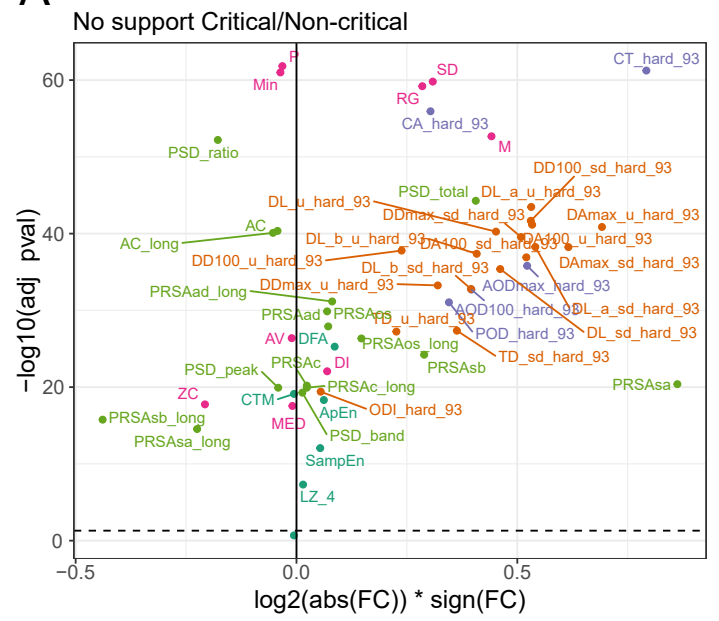

B

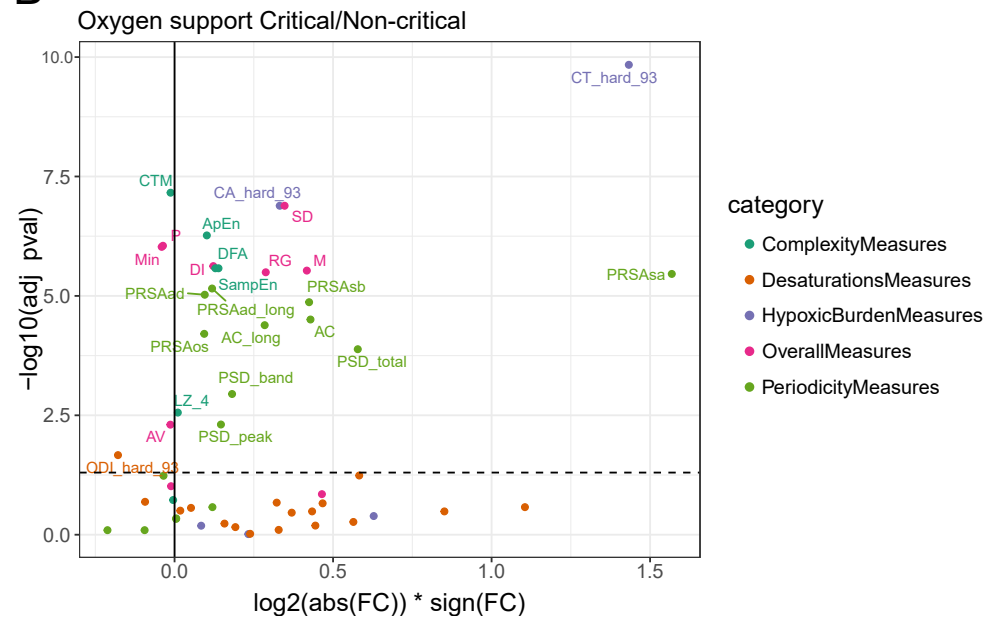

Figure 4. OBMs across the spectrum of disease severity and treatment support. A) Critic versus non-critical without support and B) critical versus non-critical under oxygen support. OBMs definition are available in Table S3. See the Figure S5 for the comparisons between no-support and oxygen support or mechanical ventilation.

critical patients. The $\mathrm{SpO} 2$ density per patient in each group (Figure 2C) revealed the variety of $\mathrm{SpO} 2$ patterns, notably in non-critical and critical patients without support. In addition, this analysis revealed that a sub-group of critical patients on oxygen support did not respond well to the therapy and thus subsequently required a mechanical ventilation support.

Desaturation analysis. Overall, based on the hypoxic burden (Figure 3A), the absolute threshold of $93 \%$ was the most discriminating between critical and non-critical groups with $\mathrm{p}$ value $<0,001$ and fold-change (FC) of 1,6 for no support and p-value $<0,05$ and 2,9 FC under oxygen support. A relative threshold of $3 \% \mathrm{SpO} 2$ was able to discriminate critical from non-critical patients without support only (p-value $<0,001$ ). Next, for the optimal definition ( $93 \%$ absolute), we compared the distribution of area, depth, and desaturation duration (Figure 6, Figure 3B) between the critical and the non-critical groups and with or without oxygen support. Interestingly, the non-critical group depicted more desaturations per hour compared to the critical groups (p-value $<0,05, \mathrm{FC} 1,8$ ). This difference was abolished by oxygen support (non-significant, NS). Similarly the depth and the "desat. time" of the desaturations were significantly more pronounced comparing the critical and non-critical groups when there was no support (p-value $<0,001$, FC 1,35). This effect was not significant under oxygen support (NS). The only desaturation parameter that showed a significant difference between those groups under oxygen support was the desaturation area (p-value < $0,05, \mathrm{FC} 1,6$ ) consistent with what we observed looking at the hypoxic burden. Overall, the critical group showed a larger depth (p-value $<0,001,1,23$ FC), area (p-value $<0,001,1,44$ FC) and "desat. time" duration (p-value $<0,001,1,35$ FC) of the events with respect to the non-critical group. Oxygen support had a limited effect on the depth and the "desat. time", no significant differences between oxygen support and no-support were observed. Mechanical ventilation depicted a strong effect by significantly reducing the frequency of de- saturations (p-value $<0,001,1,85 \mathrm{FC}$ ) and the depth (p-value $<0,05,1,21 \mathrm{FC})$.

Effect of treatment and OBMs. OBMs were investigated using a volcano plot analysis comparing between the critical and non-critical groups without support (Figure 4A). OBMs definitions are presented in Table S3. OBMs related to hypoxic burden and desaturation depicted a large effect $(\log 2$ fold change) with highly significant p-values (large $\log 10 \mathrm{p}$ values) consistent with the preceding results. Remarkably, the integral of $\mathrm{SpO} 2$ below the $93 \% \mathrm{SpO} 2(C A 93)$ and the percentage of time below the 93\% SpO2 (CT93, Figure S6) were the most discriminating OBMs. The same analysis under oxygen support (Figure 4B) revealed that most OBMs related to desaturation and hypoxic burden were not significantly different between the two groups apart from CT93 and $C A 93$. Overall, OBMs depicted reduced FDR adjusted pvalues under oxygen support. However, general and periodicity related OBMs remained significantly affected between non-critical and critical group. Next, the effect of the support was investigated (Figure S5A-C). In non-critical patients the effect of oxygen support was mild (Figure S5A). Both FC and FDR adjusted p-values ranges were smaller than in the critical versus non-critical comparison (Figure 4A). OBMs related to hypoxic burden and desaturation parameters were still higher under oxygen support (Figure S5A). In the critical group under oxygen versus no support, the picture was similar indicating that the oxygen support had only a mild effect on OBMs (Figure S5B). On the other hand (Figure S5C), mechanical ventilation depicted a more pronounced effect on OBMs, notably with a reduction of all OBMs related to hypoxic burden, desaturation parameters , periodicity and complexity.

Transition analysis and OBMs' trajectory. There were a total of 43 patients with transitions, i.e. initiation of mechanical ventilation, with a total of 68 transitions overall. Among 

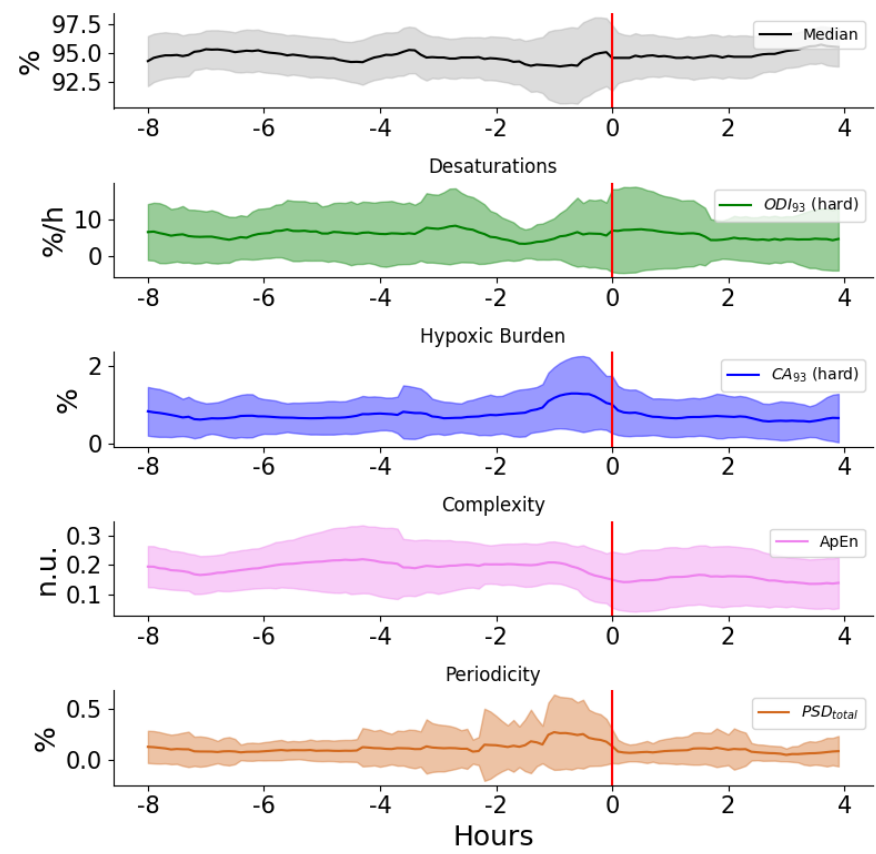

Figure 5. Temporal tracking of OBMs before and after the initiation of mechanical ventilation. OBMs were computed using a sliding windows of 30 minutes, from 8 hours before the transition, to 4 hours after it with a shift of five minutes. The median and IQR were computed over 68 transition events. For each of the five category, one biomarker with low $p$ value is represented. OBMs definition are available in Table S3

the patients that had transitions, they had a Q1 of 1, and a Q3 of 2 transitions, and the maximum number of transitions for a single patient was 3. Panel A of figure S4 shows examples of transition from three representative patients and panel B shows the average profile of every transition detected.

Temporal tracking of selected OBMs is illustrated in figure 5. The median $\mathrm{SpO} 2$ depicted a larger variation about $1 \mathrm{~h}$ before the transition. The desaturation class represented by the $O D I 93$, depicted large variations around the transition. The ODI93 showed a decreased number about one hour and a half before the transition suggesting larger desaturations in agreement with $C A 93$ (hypoxic burden) showing an increase and a high variance before the transition. Approximate entropy $A p E n$ (complexity) depicted a small reduction about 4 hours before the transition and marked decreased after the transition. Finally, $P S D_{\text {total }}$ (Periodicity) showed an increasing perturbation between 4 to 1,5 hours before the transition. Thus, the spectral band of interest $(0,014-0,033 \mathrm{~Hz})$ appeared to have a greater power than the rest of the signal, before the transition.

\section{Discussion}

The oximetry has been widely used for the management of respiratory pathologies, such as pulmonary edema, Acute respiratory distress syndrome (ARDS), pneumonia, obstructive sleep apnea $(\mathrm{OSA})^{9-12}$, and more recently, in a research setting, for nocturnal chronic obstructive pulmonary disease (COPD) diagnosis ${ }^{13}$. However, to our knowledge, no study investigated continuous high resolution $\mathrm{SpO} 2$ characteristics (patterns and dynamics) in COVID-19 patients.
Patients with COVID 19 presenting to the emergency department go through meticulous investigation (Figure 1A) that includes physical examination, laboratory tests and continuous monitoring of vital signs ${ }^{14,15}$. Depending on the results of this screening, the patient can be discharged or admitted for observation and treatment in a monitored or nonmonitored bed. Oxygen support can be applied in case of hypoxaemia ( $\mathrm{SpO} 2<94 \%$, or a drop $>3 \% \mathrm{SpO} 2)$ or in dyspnoeic patients with increased work of breathing who are at risk of respiratory failure ${ }^{16}$. In more severe cases, the patient might be transferred directly to the ICU ${ }^{17}$. If the patient shows signs of respiratory failure on admission or develops one later, they may be mechanically ventilated, or undergo an attempt of non-invasive support. Thus, multiple decisions are made by physicians in this process who need to factor both subjective observations and objective parameters such as $\mathrm{SpO}$. However, how these decisions are made and what should be taken into consideration for increasing the level of care is not always clear ${ }^{18}$. Furthermore, there is a need to sort critical from non-critical patients and identify patients' status deterioration using non-invasive measurements. Pulse oximetry offers many advantages as it is a cost effective continuous monitoring method that can be used in hospital or in a telemedicine setting ${ }^{19,20}$.

While healthy people generally depict an oximetry in the range $94 \%$ to $98 \%{ }^{21}$, critical COVID-19 patients showed higher density of low $\mathrm{SpO} 2$ (80\%-90\%) as compared to noncritical or critical ventilated patients (Figure 2). Thus several questions arise: what is an appropriate $\mathrm{SpO} 2$ threshold to distinguish critical from non-critical patients? what is a good predictor of oxygen support and mechanical ventilation? How does ventilation and oxygen support affect the $\mathrm{SpO} 2$ level and its dynamics? Several studies have started to investigate these questions. A recent study showed that a saturation below $90 \%$ correlates with a higher probability for mortality ${ }^{22}$, but this work was based on discrete measures of $\mathrm{SpO} 2$ and used death as an endpoint. Another recent investigation of $\mathrm{SpO} 2$ and the ROX score at admission concluded that an $\mathrm{SpO} 2$ below $78 \%$ was a good predictor of mechanical ventilation requirement ${ }^{6}$ and that a ROX score above 1,4 while on non-invasive ventilation was a good predictor of failure. Other trials suggested that the ratio of $\mathrm{SpO} 2$ to $\mathrm{FiO} 2$ (or $\mathrm{PaO} 2$ to FiO2) could serve as a prognostic marker and could facilitate early adjustment of treatment ${ }^{7,23,24}$.

In the present study, we motivated that a threshold of $93 \%$ best differentiates between critical and non-critical patients under no support or oxygen support. Thus, our work suggests a more stringent threshold compared to the WHO guidelines ${ }^{5}$ that define an operational threshold of $90 \% \mathrm{SpO} 2$ to define severe patients. In addition, a drop of $3 \% \mathrm{SpO} 2$ (relative threshold) was able to discriminate critical from non-critical patients without support. This is consistent with the recommendation of a prompt assessment in the emergency oxygen therapy guidelines ${ }^{16}$ as it may indicate an acute deterioration in the patient's condition. In addition, our work highlighted the differences of $\mathrm{SpO} 2$ dynamics between the critical and 
non-critical groups. Specifically, we observed that the noncritical group had frequent shallow desaturations, while critical patients had deeper and longer but less numerous desaturations (Figure 3). Our work also investigated the effect of the oxygen support, which drastically reduced the differences between the two groups. The effect of mechanical ventilation showed a reduction of the $\mathrm{SpO} 2$ signal complexity, periodicity, a lower incidence of desaturation and a higher $\mathrm{SpO} 2$ saturation level overall with a risk of over oxygenation potentially detrimental ${ }^{25,26}$.In addition, we have shown that various biomarkers and standard analysis of continuous oximetry formerly developed to study OSA or COPD ${ }^{9,13,27,28}$ may support the monitoring of COVID-19 patients. Strikingly, two OBMs related to the hypoxic burden class were most discriminative between critical and non-critical patients under no support or under oxygen support. These were: (1) the percentage of time below the $93 \%$ oxygen saturation threshold (CT93, Figure S6) and (2) the integral of the signal below the $93 \% \mathrm{SpO} 2$ level normalized by the total recording time (CA93). This results was consistent with a recent study suggesting the cumulative oxygen deficit as a predictor of mechanical ventilation ${ }^{29}$.

Our study might have important clinical implications. First, it can serve as a tool to predict the patient's trajectory while being treated in the ward using oxygen supplementation or non-invasive ventilation. $\mathrm{SpO} 2$ monitoring has the advantage of being used frequently and continuously in all patients requiring oxygen treatment, and the data can be saved and processed. Second, assessing oxygenation and desaturation patterns might serve as a prognostic tool in COVID 19 patients. Third, in an overwhelmed medical system, the decision whether to admit or discharge a patient to a ward or ICU is extremely important. Analyzing oxygenation can assist in that manner ${ }^{4,12,30}$. Finally, our results can be relevant in other medical conditions involving the respiratory system such as pulmonary infections, COPD, ARDS and more. Large scale, preferably prospective randomized trials are required to validate our results.

The presented work has several important limitations. First, our work is a single center retrospective and descriptive study. Second, we did not explore the effect of sub-type of support or stratified parameters such as FiO2, EtCO2, PEEP or pressure support levels.

We provide the first report of continuous $\mathrm{SpO} 2$ analysis in COVID-19 patients across severity categories and respiratory support levels. Continuous monitoring of $\mathrm{SpO} 2$ is of paramount importance to characterize and manage COVID19 patients. Mechanical ventilation and oxygen support have an impact on the $\mathrm{SpO} 2$ signal characteristics. Finally, OBMs improves the monitoring and enable to anticipate deterioration of the patient's status.

\section{Methods}

Study design and participants. This single center retrospective observational cohort study used electronic medical records (EMR) and continuous physiological monitoring data from Rambam Health Care Campus (HCC), a 1000-bed tertiary academic hospital in Northern Israel. During the pandemic the Rambam HCC opened five dedicated COVID-19 departments. The hospital EMR database was queried for hospitalized adult (age 18 and above) cases admitted for COVID-19, from May 1st 2020 until February 1st 2021 with at least one hour of continuous $\mathrm{SpO} 2$ recording. During this period, 1810 confirmed COVID-19 cases were admitted to the Rambam HCC (Figure S1). Most cases were mild or moderate and were not necessarily connected to a bedside monitor for continuous surveillance. Five hundred and nineteen patients above 18 years of age were monitored and 367 had more than an hour of $\mathrm{SpO} 2$ continuous measurement. Consequently, we collected continuous physiological signal from 162 critical and 205 non-critical COVID-19 patients. Identified waveform data from all COVID-19 units (ward and intensive care unit,ICU) were included. Data were extracted from MINDRAY monitors (Shenzhen, China). Using the MINDRAY software CMSViewer, the available $\mathrm{SpO} 2$ data per patient were exported with a resolution of $1 \mathrm{~Hz}$. Overall $27 \mathrm{~K}$ hours of continuous $\mathrm{SpO} 2$ signal was collected, including $15 \mathrm{~K}$ hours on patients breathing room air, $4 \mathrm{~K}$ hours of mechanically ventilated patients, and $8 \mathrm{~K}$ hours for patients under oxygen support. Preprocessing of the raw $\mathrm{SpO} 2$ signal was performed using a block filter ${ }^{28,31}$ and a smoothing moving median filter with a window of 9s. EMR data including demographics information for age, sex, weight, body mass index (BMI), length of hospitalization, disease severity, and mortality rates were collected. In addition, monitor information such as the end-tidal CO2 (ETCO2) channel for mechanical ventilation, parameters and timestamps, oxygen support and respiratory information including oxygen flow rate, and respiratory rate were collected. Ethical approval for this research was provided by the local institutional review board under IRB \#0141-20.

COVID-19 definition and severity groups. As in ReinerBenaim et al. ${ }^{32}$, and following existing guidelines ${ }^{33-35}$, COVID-19 positive patients were defined as follow: at least one positive reverse transcription polymerase chain reaction (RT-PCR) test for SARS-CoV-2 in nasopharyngeal swab. Critically ill patients were defined for their entire hospitalization as those who either received mechanical ventilation support (invasive or non-invasive), were hospitalized in an ICU, or were administered vasopressors (Noradrenaline or Vasopressin) or inotropes (Dopamine, Dobutamine, Milrinone, or Adrenaline).

Oxygen and mechanical ventilatory support. Oxygen support intervals were defined based on the first and the last continuous value of oxygen flow rate extracted from the EMR for an individual patient (Figure S2). Mechanical ventilation intervals were detected using the End-tidal $\mathrm{CO} 2$ (EtCO2) channel from the monitors. The EtCO2, which measures the partial pressure of $\mathrm{CO} 2$ at end expirium, is recorded only in mechanically ventilated patients. The $\mathrm{SpO} 2$ data were split according to an overlap with these predefined intervals. Oxy- 
gen delivery and ventilation modes were recorded, including continuous positive airway pressure (CPAP), bi-level positive airway pressure (BIPAP), mask, nasal prongs, T-tube and a tracheostomy mask. Several equipment types were used, notably ventilators such as Hamilton (Hamilton Medical, Bonaduz, Switzerland), ServoAIR, Servo I (Getinge, Gothenburg, Sweden), EVITA (Dräger,Lübeck, Germany), VELA (VYAIRE MEDICAL INC., Chicago, Illinois, United States) and high flow oxygen delivery devices such as Airvo2 (Fisher and Paykel, Auckland, New Zealand) and Vapotherm (Vapotherm Inc., Exeter, New Hampshire, United States).

\section{Events definition.}

Desaturation events. Two categories of desaturations can be defined: (1) "relative" desaturations corresponding to a decrease of $\mathrm{x} \%$ (here taken as $3 \%$ or $5 \%$ ) of the $\mathrm{SpO} 2$ signal, before returning to $1 \%$ below the initial saturation level. The relative threshold desaturation detector is based on the Oxygen Desaturation Index (ODI) which is traditionally used in sleep medicine. The ODI algorithm from Jung et al. ${ }^{36}$ was used with its implementation and validation by Behar et al. ${ }^{37}$; (2) "hard" desaturations defined as $\mathrm{SpO} 2$ level falling below a given threshold of $\mathrm{x} \% \mathrm{SpO} 2$ (here taken as $93 \%, 90 \%$ or $88 \%$ ). When the $\mathrm{SpO} 2$ signal falls below this value, a desaturation is detected. Figure 6 presents examples of desaturations detected using the hard threshold and relative threshold. The event has to be of a minimum length of $120 \mathrm{sec}-$ onds. This is to be considered a desaturation event to avoid a false positive reading caused by the patient's movements or noise. For each detected desaturation, several desaturation parameters were extracted. Specifically area, length, depth, time between the beginning and the minimum point (defined as desat. time), the time between the minimum and the end (defined as resat. time) and the duration between two consecutive desaturations (interval time).

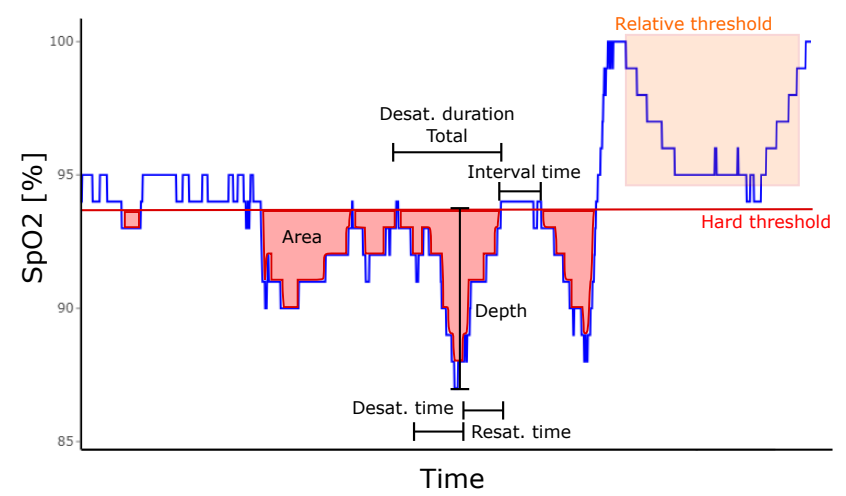

Figure 6. Example of $\mathrm{SpO} 2$ signal with desaturation parameters highlighted. Here the hard threshold is at $93 \%$ and the relative threshold is of $5 \%$.

Transition to mechanical ventilation event. For each patient in the critical group, the time of initiation of mechanical ventilation was extracted on the EtCO2 channel using a sliding window procedure. Briefly, two consecutive windows of five seconds long were created. When sliding the two consecutive windows over the $\mathrm{CO} 2$ signal, if the first one had no signal within it whereas the second one had only valid values within it, this was labeled as an event of transition to mechanical ventilation.

Oximetry biomarkers (OBMs). OBMs were extracted from the $\mathrm{SpO} 2$ signal with a sampling frequency of $1 \mathrm{~Hz}$. As previously described by Levy et al. ${ }^{27}$, OBMs definitions are presented in Table S3. these biomarkers are divided into 5 categories: (1) General Statistics: time-based statistics describing the $\mathrm{SpO} 2$ data distribution; (2) Complexity: quantifies the presence of long-range correlations in non-stationary signal; (3) Periodicity: quantifies consecutive events to identify periodicity in the SpO2 signal; (4) Desaturations: time-based descriptive measures of the desaturation patterns occurring throughout the signal; (5) Hypoxic Burden: time-based measures quantifying the overall degree of hypoxemia imposed on the heart and other organs during the recording period.

\section{Statistical Analysis.}

Cohort. Comorbidities and demographics including age, weight, BMI, length of stay and death were collected. Comorbidities were defined by ICD-9 codes and analysed as by Benaim et $\mathrm{al}^{32}$. A thorough analysis of comorbidities, demographics and mortality rate was performed to characterize predispositions for both the critical and non-critical group. Demographic variables and comorbidity rates, were compared between severity groups using the Chi-squared test or Fisher's exact test for categorical variables, and analysis of variance or Kruskal-Wallis test for continuous variables. The p-values across all tests were corrected to control the false discovery rate (FDR) criterion ${ }^{38}$. Medians and inter-quartile range (IQR) were used to describe the continuous variables.

SpO2 global characteristics. The $\mathrm{SpO} 2$ signal was summarised using a density of $\mathrm{SpO} 2$ for each group of patients investigated. In addition, the $\mathrm{SpO} 2$ density was computed per patient and support interval and was represented in a heatmap sorted by SpO2 mean for each group.

Desaturation characteristics. In order to decide which desaturation definition was the most clinically relevant, we studied the hypoxic burden as a function of each threshold (Figure $3 \mathrm{~A})$. The hypoxic burden was defined by the sum of areas of desaturations per hours for a given patient. The characteristics of the desaturation between each group were compared using the Wilcoxon test.

OBMs comparisons across severity and support level. The OBM toolbox ${ }^{27}$ was used to extract OBMs from the $\mathrm{SpO} 2$ signal using consecutive and non-overlapping windows of $1 \mathrm{~h}$. The average of each OBM per patient and under each support was computed for analysis. OBMs were used to discriminate between critical and non critical patients and characterize the effects of mechanical ventilation and oxygen support on the $\mathrm{SpO} 2$ signal. The goal of this last analysis was to determine the influence of oxygen support or mechanical ventilation on 
medRxiv preprint doi: https://doi.org/10.1101/2021.09.26.21264135; this version posted November 8, 2021. The copyright holder for this preprint (which was not certified by peer review) is the author/funder, who has granted medRxiv a license to display the preprint in perpetuity. It is made available under a CC-BY-ND 4.0 International license .

the $\mathrm{SpO} 2$ signal. Groups OBMs were compared using using the Wilcoxon test.

OBMs and transition events. A sliding window of 30 minutes with a shift of 5 min was applied on the $\mathrm{SpO} 2$ signal $8 \mathrm{~h}$ before to $4 \mathrm{~h}$ after transitions to study the dynamic of the signal and identify candidate OBMs anticipating a deterioration of the patient requiring intubation and mechanical ventilation. The median and the interquartile range of all transitions are represented for selected OBMs that depicted large variations before the transition.

The $\mathrm{R}$ software ${ }^{39}$ was used for statistical analysis. A significance threshold at 0,05 was used.

\section{Contributors}

J.S., J.B., R.A., A.R.B., and D.E. were involved in the conception and design of the study. J.S: was the coordinator of the study. J.S., R.A., A.M. and A.R.B were responsible for the data collection. J.S. and J.B. wrote the first draft. J.S., J.L. and A.R.B. were in charge of the analysis. A.R.B and R.A. accessed and verified the data. All authors were involved in the interpretation, critically reviewed the first draft, and approved the final version.

\section{Declaration of interests}

The authors declare that there is no conflict of interest.

\section{Data sharing}

The anonymised database including the waveforms and the clinical data from the COVID-19 patients will be accessible upon reasonable request, which will be individually reviewed by the ethical committee of the Rambam HCC.

\section{Code availability}

The source code used in this research is available at physiozoo.com.

\section{ACKNOWLEDGEMENTS}

This research is partially supported by The Milner Foundation, founded by Yuri Milner and his wife Julia. We are grateful to the Placide Nicod fundation for their financial support (J.S.). We acknowledge the financial support of the Technion Machine Learning and Intelligent Systems center (MLIS). We would like to thank Prof. Pierre Singer for insightful discussion regarding the present work. We are grateful to the care team from the COVID-19 units of Rambam HCC.

\section{Bibliography}

1. Zunyou Wu and Jennifer M. McGoogan. Characteristics of and Important Lessons From the Coronavirus Disease 2019 (COVID-19) Outbreak in China: Summary of a Report of 72314 Cases From the Chinese Center for Disease Control and Prevention. JAMA, 323 (13):1239-1242, 04 2020. ISSN 0098-7484. doi: 10.1001/jama.2020.2648.

2. Gregory A. Roth, Sophia Emmons-Bell, Heather M. Alger, Steven M. Bradley, Sandeep R Das, James A de Lemos, Emmanuela Gakidou, Mitchell S. V. Elkind, Simon Hay, Jennifer L. Hall, Catherine O. Johnson, David A. Morrow, Fatima Rodriguez, Christine Rutan, Saate Shakil, Reed Sorensen, Laura Stevens, Tracy Y. Wang, Jason Walchok, Joseph Williams, and Christopher Murray. Trends in Patient Characteristics and COVID-19 In-Hospital Mortality in the United States During the COVID-19 Pandemic. JAMA Network Open, 4(5): e218828-e218828, 05 2021. ISSN 2574-3805. doi: 10.1001/jamanetworkopen.2021.8828.

3. Megan O'Driscoll, Gabriel Ribeiro Dos Santos, Lin Wang, Derek AT Cummings, Andrew S Azman, Juliette Paireau, Arnaud Fontanet, Simon Cauchemez, and Henrik Salje. Agespecific mortality and immunity patterns of sars-cov-2 infection in 45 countries. medRxiv, 2020
4. Arvin R Akhavan, Joseph P Habboushe, Rajneesh Gulati, Oluchi Iheagwara, Joanna Watterson, Shawn Thomas, Jordan L Swartz, Christian A Koziatek, and David C Lee. Risk stratification of covid-19 patients using ambulatory oxygen saturation in the emergency department. Western Journal of Emergency Medicine, 21(6):5, 2020.

5. Covid-19 clinical management: living guidance, 2021.

6. Ahmed Mukhtar, Ashraf Rady, Ahmed Hasanin, Ahmed Lotfy, Akram El Adawy, Amr Hussein, Islam El-Hefnawy, Mohamed Hassan, and Hanan Mostafa. Admission spo2 and rox index predict outcome in patients with covid-19. The American Journal of Emergency Medicine, 2021.

7. Ana Alberdi-lglesias, Francisco Martín-Rodríguez, Guillermo Ortega Rabbione, Ana Rubio-Babiano, María G Núñez-Toste, Ancor Sanz-García, Carlos del Pozo Vegas, Miguel A Castro Villamor, José L Martín-Conty, Cristina Jorge-Soto, et al. Role of spo2/fio2 ratio and rox index in predicting early invasive mechanical ventilation in covid-19. a pragmatic, retrospective, multi-center study. Biomedicines, 9(8):1036, 2021.

8. Carolina Panadero, Araceli Abad-Fernández, $M^{a}$ Teresa Rio-Ramirez, Carmen Maria Acosta Gutierrez, Mariara Calderon-Alcala, Cristina Lopez-Riolobos, Cristina Matesanz-Lopez, Fernando Garcia-Prieto, Jose Maria Diaz-Garcia, Beatriz RabosoMoreno, et al. High-flow nasal cannula for acute respiratory distress syndrome (ards) due to covid-19. Multidisciplinary respiratory medicine, 15(1), 2020.

9. Philip I Terrill. A review of approaches for analysing obstructive sleep apnoea-related patterns in pulse oximetry data. Respirology, 25(5):475-485, 2020.

10. Joachim A Behar, Niclas Palmius, Qiao Li, Silverio Garbuio, Fabìola PG Rizzatti, Lia Bittencourt, Sergio Tufik, and Gari D Clifford. Feasibility of single channel oximetry for mass screening of obstructive sleep apnea. EClinicalMedicine, 11:81-88, 2019.

11. Francisco Sanz, Nathan Dean, Justin Dickerson, Barbara Jones, Daniel Knox, Estrella Fernández-Fabrellas, Eusebi Chiner, María Luisa Briones, Ángela Cervera, María Carmen Aguar, et al. Accuracy of pao 2/fio 2 calculated from spo 2 for severity assessment in ed patients with pneumonia. Respirology, 20(5):813-818, 2015.

12. William R Mower, Carolyn Sachs, Emily L Nicklin, Parsa Safa, and Larry J Baraff. Effect of routine emergency department triage pulse oximetry screening on medical management. Chest, 108(5):1297-1302, 1995.

13. Jeremy Levy, Daniel Álvarez, Felix del Campo, and Joachim A Behar. Machine learning for nocturnal diagnosis of chronic obstructive pulmonary disease using digital oximetry biomarkers. Physiological Measurement, 42(5):054001, may 2021. doi: 10.1088/1361-6579/ abf5ad.

14. Rajesh T. Gandhi, John B. Lynch, and Carlos del Rio. Mild or moderate covid-19. New England Journal of Medicine, 383(18):1757-1766, 2020. doi: 10.1056/NEJMcp2009249.

15. Thirumalaisamy $P$ Velavan and Christian G Meyer. Mild versus severe covid-19: laboratory markers. International Journal of Infectious Diseases, 95:304-307, 2020.

16. Binita Kane, Samantha Decalmer, and B Ronan O'Driscoll. Emergency oxygen therapy: from guideline to implementation. Breathe, 9(4):246-253, 2013.

17. Jean-Louis Vincent. The continuum of critical care. Critical Care, 23(1):1-5, 2019.

18. Niraj Shenoy, Rebecca Luchtel, and Perminder Gulani. Considerations for target oxygen saturation in covid-19 patients: are we under-shooting? BMC medicine, 18(1):1-6, 2020.

19. Trisha Greenhalgh, Matthew Knight, Matt Inada-Kim, Naomi J Fulop, Jonathan Leach, and Cecilia Vindrola-Padros. Remote management of covid-19 using home pulse oximetry and virtual ward support. BMJ, 372, 2021. doi: 10.1136/bmj.n677.

20. Judd E. Hollander and Brendan G. Carr. Virtually perfect? telemedicine for covid-19. New England Journal of Medicine, 382(18):1679-1681, 2020. doi: 10.1056/NEJMp2003539.

21. Amar S Bhogal and Ali R Mani. Pattern analysis of oxygen saturation variability in healthy individuals: Entropy of pulse oximetry signals carries information about mean oxygen saturation. Frontiers in physiology, 8:555, 2017.

22. Jiang Xie, Naima Covassin, Zhengyang Fan, Prachi Singh, Wei Gao, Guangxi Li, Tomas Kara, and Virend K Somers. Association between hypoxemia and mortality in patients with covid-19. In Mayo Clinic Proceedings, volume 95, pages 1138-1147. Elsevier, 2020.

23. Xiaofan Lu, Liyun Jiang, Taige Chen, Yang Wang, Bing Zhang, Yizhou Hong, Jun Wang, and Fangrong Yan. Continuously available ratio of spo 2/fio 2 serves as a noninvasive prognostic marker for intensive care patients with covid-19. Respiratory Research, 21(1):1-4, 2020.

24. Pierachille Santus, Dejan Radovanovic, Laura Saderi, Pietro Marino, Chiara Cogliati, Giuseppe De Filippis, Maurizio Rizzi, Elisa Franceschi, Stefano Pini, Fabio Giuliani, et al. Severity of respiratory failure at admission and in-hospital mortality in patients with covid-19: a prospective observational multicentre study. BMJ open, 10(10):e043651, 2020.

25. Pierce Geoghegan, Sean Keane, and Ignacio Martin-Loeches. Change is in the air: dying to breathe oxygen in acute respiratory distress syndrome? Journal of thoracic disease, 10 (Suppl 18):S2133, 2018

26. Massimo Girardis, Stefano Busani, Elisa Damiani, Abele Donati, Laura Rinaldi, Andrea Marudi, Andrea Morelli, Massimo Antonelli, and Mervyn Singer. Effect of Conservative vs Conventional Oxygen Therapy on Mortality Among Patients in an Intensive Care Unit: The Oxygen-ICU Randomized Clinical Trial. JAMA, 316(15):1583-1589, 10 2016. ISSN 00987484. doi: 10.1001/jama.2016.11993.

27. Jeremy Levy, Daniel Álvarez, Aviv A Rosenberg, Alexandra Alexandrovich, Félix Del Campo, and Joachim A Behar. Digital oximetry biomarkers for assessing respiratory function: standards of measurement, physiological interpretation, and clinical use. npj Digital Medicine, 4 (1):1-14, 2020.

28. Joren Buekers, Jan Theunis, Patrick De Boever, Anouk W Vaes, Maud Koopman, Eefje VM Janssen, Emiel FM Wouters, Martijn A Spruit, and Jean-Marie Aerts. Wearable finger pulse oximetry for continuous oxygen saturation measurements during daily home routines of patients with chronic obstructive pulmonary disease (copd) over one week: Observational study. JMIR Mhealth Uhealth, 7(6):e12866, Jun 2019. ISSN 2291-5222. doi: 10.2196/12866.

29. Huiqing Ge, Jian-cang Zhou, FangFang Lv, Junli Zhang, Jun Yi, Changming Yang, Lingwe Zhang, Yuhan Zhou, Binbin Ren, Qing Pan, et al. Cumulative oxygen deficit is a novel predictor for the timing of invasive mechanical ventilation in covid-19 patients with respiratory distress. PeerJ, 8:e10497, 2020.

30. Sonia Shah, Kaushal Majmudar, Amy Stein, Nita Gupta, Spencer Suppes, Marina Karamanis, Joseph Capannari, Sanjay Sethi, and Christine Patte. Novel use of home pulse oximetry monitoring in covid-19 patients discharged from the emergency department identifies need 
medRxiv preprint doi: https://doi.org/10.1101/2021.09.26.21264135; this version posted November 8, 2021. The copyright holder for this preprint (which was not certified by peer review) is the author/funder, who has granted medRxiv a license to display the preprint in perpetuity.

It is made available under a CC-BY-ND 4.0 International license .

for hospitalization. Academic Emergency Medicine, 27(8):681-692, 2020.

31. Aviv A. Rosenberg Felix del Campo Jeremy Levy, Daniel Álvarez and Joachim A. Behar. Oximetry digital biomarkers for assessing respiratory function during sleep: standards of measurement, physiological interpretation, and clinical use. Nature, 60(6):1660-1666, 2020.

32. Anat Reiner Benaim, Jonathan Aryeh Sobel, Ronit Almog, Snir Lugassy, Tsviel Ben Shabbat, Alistair Johnson, Danny Eytan, and Joachim A Behar. At the dawn of winter: comparing covid-19 and influenza presentation and trajectory. medRxiv, 2020.

33. David A Berlin, Roy M Gulick, and Fernando J Martinez. Severe covid-19. New England Journal of Medicine, 2020.

34. Management of persons with covid-19. https:// www.covid19treatmentguidelines.nih.gov/overview/ management-of-covid-19, 2020.

35. Clinical management of covid-19: interim guidance, 2020.

36. D. W. Jung, S. H. Hwang, J. G. Cho, B. H. Choi, H. J. Baek, Y. J. Lee, D. U. Jeong, and K. S. Park. Real-time automatic apneic event detection using nocturnal pulse oximetry. IEEE Transactions on Biomedical Engineering, 65(3):706-712, 2018. doi: 10.1109/TBME.2017. 2715405.

37. Joachim A Behar, Niclas Palmius, Sroussi Zacharie, Armand Chocron, Thomas Penzel, Lia Bittencourt, and Sergio Tufik. Single-channel oximetry monitor versus in-lab polysomnography oximetry analysis: does it make a difference? Physiological Measurement, 41(4): 044007, 2020.

38. Yoav Benjamini and Yosef Hochberg. Controlling the false discovery rate: A practical and powerful approach to multiple testing. Journal of the Royal Statistical Society. Series $B$ (Methodological), 57(1):289-300, 1995. ISSN 00359246.

39. R Core Team. R: A Language and Environment for Statistical Computing. R Foundation for Statistical Computing, Vienna, Austria, 2018. 
medRxiv preprint doi: https://doi.org/10.1101/2021.09.26.21264135; this version posted November 8, 2021. The copyright holder for this preprint (which was not certified by peer review) is the author/funder, who has granted medRxiv a license to display the preprint in perpetuity.

It is made available under a CC-BY-ND 4.0 International license.

\section{Supplementary Information}

Table S1. Critical and non-critical patient characteristics: demographic, length of stay, and respiratory parameters at admission.

\begin{tabular}{|c|c|c|c|c|c|c|c|c|c|c|}
\hline variable & group & $\mathrm{n}$ & mean & median & Q1 & Q3 & IQR & std & FDR adjusted $\mathrm{p}$-value & test \\
\hline age [year] & $\begin{array}{l}\text { non-critical } \\
\text { critical }\end{array}$ & $\begin{array}{l}205 \\
162\end{array}$ & $\begin{array}{l}63,05 \\
66,81\end{array}$ & $\begin{array}{l}64,00 \\
68,87\end{array}$ & $\begin{array}{l}52,08 \\
55,64\end{array}$ & $\begin{array}{l}76,00 \\
77,83\end{array}$ & $\begin{array}{l}23,92 \\
22,18\end{array}$ & $\begin{array}{l}17,17 \\
14,54\end{array}$ & 0,084 & ANOVA \\
\hline length of stay [day] & $\begin{array}{l}\text { non-critical } \\
\text { critical }\end{array}$ & $\begin{array}{l}205 \\
162\end{array}$ & $\begin{array}{l}6,72 \\
18,17\end{array}$ & $\begin{array}{l}5 \\
14\end{array}$ & $\begin{array}{l}3,00 \\
8,25\end{array}$ & $\begin{array}{l}8,00 \\
21,75\end{array}$ & $\begin{array}{l}5,0 \\
13,5\end{array}$ & $\begin{array}{l}6,73 \\
15,37\end{array}$ & $8,50 \mathrm{e}-26$ & Kruskal-Wallis test \\
\hline weight $[\mathrm{Kg}]$ & $\begin{array}{l}\text { non-critical } \\
\text { critical }\end{array}$ & $\begin{array}{l}194 \\
157\end{array}$ & $\begin{array}{l}84,37 \\
87,96\end{array}$ & $\begin{array}{l}82 \\
88\end{array}$ & $\begin{array}{l}72 \\
75\end{array}$ & $\begin{array}{l}95 \\
100\end{array}$ & $\begin{array}{l}23 \\
25\end{array}$ & $\begin{array}{l}20,24 \\
18,84\end{array}$ & 0,20 & ANOVA \\
\hline BMI & $\begin{array}{l}\text { non-critical } \\
\text { critical }\end{array}$ & $\begin{array}{l}194 \\
157\end{array}$ & $\begin{array}{l}29,21 \\
30,06\end{array}$ & $\begin{array}{l}28,7 \\
29,4 \\
\end{array}$ & $\begin{array}{l}25,35 \\
25,90\end{array}$ & $\begin{array}{l}32,37 \\
33,10\end{array}$ & $\begin{array}{l}7,02 \\
7,200\end{array}$ & $\begin{array}{l}5,18 \\
5,37\end{array}$ & 0,28 & Kruskal-Wallis test \\
\hline room saturation [\%] & $\begin{array}{l}\text { non-critical } \\
\text { critical }\end{array}$ & $\begin{array}{l}205 \\
148\end{array}$ & $\begin{array}{l}93,34 \\
89,31\end{array}$ & $\begin{array}{l}94,0 \\
90,5\end{array}$ & $\begin{array}{l}91 \\
85\end{array}$ & $\begin{array}{l}97,00 \\
94,25\end{array}$ & $\begin{array}{l}6,00 \\
9,25\end{array}$ & $\begin{array}{l}4,40 \\
6,24\end{array}$ & $2,43 e-09$ & Kruskal-Wallis test \\
\hline oxygen saturation [\%] & $\begin{array}{l}\text { non-critical } \\
\text { critical }\end{array}$ & $\begin{array}{l}145 \\
157\end{array}$ & $\begin{array}{l}95,97 \\
94,67\end{array}$ & $\begin{array}{l}96 \\
95\end{array}$ & $\begin{array}{l}95 \\
93\end{array}$ & $\begin{array}{l}98 \\
97\end{array}$ & $\begin{array}{l}3 \\
4\end{array}$ & $\begin{array}{l}1,96 \\
3,83\end{array}$ & 0,03 & Kruskal-Wallis test \\
\hline breaths number & $\begin{array}{l}\text { non-critical } \\
\text { critical }\end{array}$ & $\begin{array}{l}182 \\
162\end{array}$ & $\begin{array}{l}18,29 \\
21,59\end{array}$ & $\begin{array}{l}18 \\
20\end{array}$ & $\begin{array}{l}15 \\
18\end{array}$ & $\begin{array}{l}20,00 \\
24,75\end{array}$ & $\begin{array}{l}5,00 \\
6,75\end{array}$ & $\begin{array}{l}4,76 \\
6,56\end{array}$ & $3,03 \mathrm{e}-07$ & Kruskal-Wallis test \\
\hline
\end{tabular}


Table S2. Comorbidities prevalence among study patients at admission and comparison between critical and non-critical groups.

\begin{tabular}{|c|c|c|c|c|c|c|}
\hline variable & & non-critical & & critical & & $\overline{\text { FDR adjusted } \mathrm{p} \text {-value }}$ \\
\hline & & $(n=205)$ & & $(n=162)$ & & \\
\hline \multirow[t]{2}{*}{ cancer ALL } & FALSE & 190 & $(92,7 \%)$ & 145 & $(89,5 \%)$ & 0,48 \\
\hline & TRUE & 15 & $(7,3 \%)$ & 17 & $(10,5 \%)$ & \\
\hline \multirow[t]{2}{*}{ cancer SOLID } & FALSE & 191 & $(93,2 \%)$ & 146 & $(90,1 \%)$ & 0,45 \\
\hline & TRUE & 14 & $(6,8 \%)$ & 16 & $(9,9 \%)$ & \\
\hline \multirow[t]{2}{*}{ cancer HEMATOLOGIC } & FALSE & 204 & $(99,5 \%)$ & 160 & $(98,8 \%)$ & 0,69 \\
\hline & TRUE & 1 & $(0,5 \%)$ & 2 & $(1,2 \%)$ & \\
\hline \multirow[t]{2}{*}{ acute renal failure } & FALSE & 199 & $(97,1 \%)$ & 153 & $(94,4 \%)$ & 0,40 \\
\hline & TRUE & 6 & $(2,9 \%)$ & 9 & $(5,6 \%)$ & \\
\hline \multirow[t]{2}{*}{ CKD } & FALSE & 183 & $(89,3 \%)$ & 132 & $(81,5 \%)$ & 0,14 \\
\hline & TRUE & 22 & $(10,7 \%)$ & 30 & $(18,5 \%)$ & \\
\hline \multirow[t]{2}{*}{ asthma and bronchiectasis } & FALSE & 197 & $(96,1 \%)$ & 158 & $(97,5 \%)$ & 0,68 \\
\hline & TRUE & 8 & $(3,9 \%)$ & 4 & $(2,5 \%)$ & \\
\hline \multirow[t]{2}{*}{ COPD } & FALSE & 195 & $(95,1 \%)$ & 153 & $(94,4 \%)$ & 0,81 \\
\hline & TRUE & 10 & $(4,9 \%)$ & 9 & $(5,6 \%)$ & \\
\hline \multirow[t]{2}{*}{ dementia } & FALSE & 201 & $(98 \%)$ & 155 & $(95,7 \%)$ & 0,36 \\
\hline & TRUE & 4 & $(2 \%)$ & 7 & $(4,3 \%)$ & \\
\hline \multirow[t]{2}{*}{ diabetes } & FALSE & 137 & $(66,8 \%)$ & 93 & $(57,4 \%)$ & 0,20 \\
\hline & TRUE & 68 & $(33,2 \%)$ & 69 & $(42,6 \%)$ & \\
\hline \multirow[t]{2}{*}{ hypertension } & FALSE & 102 & $(49,8 \%)$ & 76 & $(46,9 \%)$ & 0,74 \\
\hline & TRUE & 103 & $(50,2 \%)$ & 86 & $(53,1 \%)$ & \\
\hline \multirow[t]{2}{*}{ hyperlipidemia } & FALSE & 133 & $(64,9 \%)$ & 85 & $(52,5 \%)$ & 0,07 \\
\hline & TRUE & 72 & $(35,1 \%)$ & 77 & $(47,5 \%)$ & \\
\hline \multirow[t]{2}{*}{ ischemic heart disease } & FALSE & 178 & $(86,8 \%)$ & 138 & $(85,2 \%)$ & 0,78 \\
\hline & TRUE & 27 & $(13,2 \%)$ & 24 & $(14,8 \%)$ & \\
\hline \multirow[t]{2}{*}{ cardiovascular disease } & FALSE & 83 & $(40,5 \%)$ & 52 & $(32,1 \%)$ & 0,22 \\
\hline & TRUE & 122 & $(59,5 \%)$ & 110 & $(67,9 \%)$ & \\
\hline \multirow[t]{2}{*}{ smoking } & FALSE & 181 & $(88,3 \%)$ & 140 & $(86,4 \%)$ & 0,75 \\
\hline & TRUE & 24 & $(11,7 \%)$ & 22 & $(13,6 \%)$ & \\
\hline \multirow[t]{2}{*}{ stroke } & FALSE & 189 & $(92,2 \%)$ & 143 & $(88,3 \%)$ & 0,36 \\
\hline & TRUE & 16 & $(7,8 \%)$ & 19 & $(11,7 \%)$ & \\
\hline
\end{tabular}


medRxiv preprint doi: https://doi.org/10.1101/2021.09.26.21264135; this version posted November 8, 2021. The copyright holder for this preprint (which was not certified by peer review) is the author/funder, who has granted medRxiv a license to display the preprint in perpetuity. It is made available under a CC-BY-ND 4.0 International license .

Table S3. Oximetry derived biomarkers (OBMs) definitions adapted from levy et al. ${ }^{27}$

\begin{tabular}{|c|c|c|c|}
\hline Biomarker (OBMs) & Category & Definition & Unit \\
\hline CT_hard_93 & HypoxicBurdenMeasures & $\begin{array}{l}\text { Cumulative time below the } x \% \text { oxygen saturation level normalized by the total } \\
\text { recording time, by default } x=90 \text {. here } x=93\end{array}$ & $\%$ \\
\hline POD_hard_93 & HypoxicBurdenMeasures & $\begin{array}{l}\text { Time of oxygen desaturation event, normalized by the total recording time, by } \\
\text { default } x=3\end{array}$ & s \\
\hline AODmax_hard_93 & HypoxicBurdenMeasures & $\begin{array}{l}\text { The area under the oxygen desaturation event curve, using the maximum } \mathrm{SpO} 2 \\
\text { value as baseline and normalized by the total recording time }\end{array}$ & $\%$ \\
\hline ODI_hard_93 & DesaturationsMeasures & The oxygen desaturation index & event/h \\
\hline DL_u_hard_93 & DesaturationsMeasures & Mean of desaturations length & $\mathrm{s}$ \\
\hline DL_sd_hard_93 & DesaturationsMeasures & Standard deviation of desaturations length & $\mathrm{s} * \mathrm{~s}$ \\
\hline DA100_u_hard_93 & DesaturationsMeasures & $\begin{array}{l}\text { Desaturation area: mean of desaturation area under the } 100 \% \mathrm{SpO} 2 \text { level as } \\
\text { baseline }\end{array}$ & $\% * \mathrm{~s}$ \\
\hline DA100_sd_hard_93 & DesaturationsMeasures & Standard deviation of desaturation area under the $100 \% \mathrm{SpO} 2$ level as baseline & $\% * \% * s * s$ \\
\hline DD100_sd_hard_93 & DesaturationsMeasures & Standard deviation of desaturations depth using $100 \% \mathrm{SpO} 2$ level as baseline & $\% * \%$ \\
\hline DDmax_u_hard_93 & DesaturationsMeasures & Mean of desaturations depth & $\%$ \\
\hline DDmax_sd_hard_93 & DesaturationsMeasures & Standard deviation of desaturation depth & $\% * \%$ \\
\hline DS_u_hard_93 & DesaturationsMeasures & Mean of the desaturation slope & $\% / \mathrm{s}$ \\
\hline DS_sd_hard_93 & DesaturationsMeasures & Standard deviation of the desaturation slope & $(\% * \%) /(\mathrm{s} * \mathrm{~s})$ \\
\hline TD_u_hard_93 & DesaturationsMeasures & Mean of time between two consecutive desaturation events & $\mathrm{s}$ \\
\hline TD_sd_hard_93 & DesaturationsMeasures & Standard deviation of time between two consecutive desaturation events & $\mathrm{s}^{*} \mathrm{~s}$ \\
\hline DL_a_u_hard_93 & DesaturationsMeasures & Mean of length from the beginning of the desaturations to the lower point & $\mathrm{s}$ \\
\hline DL_a_sd_hard_93 & DesaturationsMeasures & $\begin{array}{l}\text { Standard deviation of length from the beginning of the desaturations to the lower } \\
\text { point }\end{array}$ & s*s \\
\hline DL_b_u_hard_93 & DesaturationsMeasures & Mean of length from the lower point of the desaturations to the end & s \\
\hline DL_b_sd_hard_93 & DesaturationsMeasures & Standard deviation of length from the lower point of the desaturations to the end & $s^{*} \mathrm{~s}$ \\
\hline AV & OverallMeasures & Blood oxygen saturation $(\mathrm{SpO} 2)$ mean & $\%$ \\
\hline PRSAc & PeriodicityMeasures & $\begin{array}{l}\text { Phase-rectified signal averaging (PRSA) capacity. With } d \text { the fragment dura- } \\
\text { tion, here } d=10\end{array}$ & $\%$ \\
\hline PRSAad & PeriodicityMeasures & PRSA amplitude difference. With $\mathrm{d}$ the fragment duration, here $\mathrm{d}=10$ & $\%$ \\
\hline PRSAos & PeriodicityMeasures & PRSA overall slope. With $\mathrm{d}$ the fragment duration, here $\mathrm{d}=10$ & $\% / \mathrm{s}$ \\
\hline PRSAsb & PeriodicityMeasures & PRSA slope before the anchor point. With $\mathrm{d}$ the fragment duration, here $\mathrm{d}=10$ & $\% / \mathrm{s}$ \\
\hline PRSAsa & PeriodicityMeasures & PRSA slope after the anchor point. With $d$ the fragment duration, here $d=10$ & $\% / \mathrm{s}$ \\
\hline $\mathrm{AC}$ & PeriodicityMeasures & Autocorrelation & $\% * \%$ \\
\hline PRSAc_long & PeriodicityMeasures & $\begin{array}{l}\text { Phase-rectified signal averaging (PRSA) capacity. With } d \text { the fragment dura- } \\
\text { tion, here } d=20\end{array}$ & $\%$ \\
\hline PRSAad_long & PeriodicityMeasures & PRSA amplitude difference. With $\mathrm{d}$ the fragment duration, here $\mathrm{d}=20$ & $\%$ \\
\hline PRSAos_long & PeriodicityMeasures & PRSA overall slope. With $d$ the fragment duration, here $d=20$ & $\% / \mathrm{s}$ \\
\hline PRSAsb_long & PeriodicityMeasures & PRSA slope before the anchor point. With $d$ the fragment duration, here $d=20$ & $\% / \mathrm{s}$ \\
\hline PRSAsa_long & PeriodicityMeasures & PRSA slope after the anchor point. With $d$ the fragment duration, here $d=20$ & $\% / \mathrm{s}$ \\
\hline PSD_total & PeriodicityMeasures & The integral of the power spectral density (PSD) function & $\%$ \\
\hline PSD_band & PeriodicityMeasures & The integral of the PSD function within the band $0,0140,033 \mathrm{~Hz}$ & $\%$ \\
\hline PSD_ratio & PeriodicityMeasures & $\begin{array}{l}\text { The integral of the PSD function within the band } 0,0140,033 \mathrm{~Hz} \text { with respect to } \\
\text { the total integral }\end{array}$ & nu \\
\hline PSD_peak & PeriodicityMeasures & Peak amplitude of the PSD function within the band $0,0140,033 \mathrm{~Hz}$ & $\%$ \\
\hline ApEn & ComplexityMeasures & $\begin{array}{l}\text { Approximate entropy with, by default, } \mathrm{m}=1, \mathrm{r}=0,25 \text { times the standard deviation } \\
\text { of the data }\end{array}$ & nu \\
\hline LZ & ComplexityMeasures & Lempel-Ziv complexity & nu \\
\hline CTM & ComplexityMeasures & Central tendency measure with radius $\rho$, by default $\rho=0,25$ & nu \\
\hline SampEn & ComplexityMeasures & Sample entropy with, by default, $m=1, r=0,25$ & nu \\
\hline DFA & ComplexityMeasures & Detrended fluctuation analysis with, by default, $n=20$ & $\%$ \\
\hline
\end{tabular}




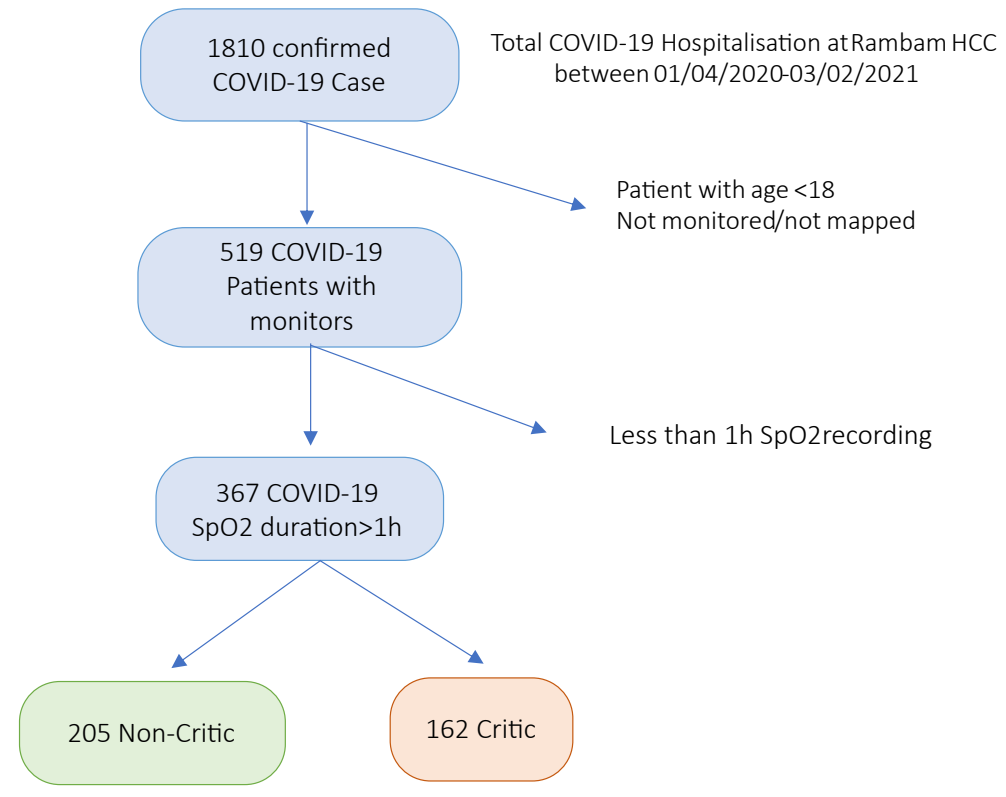

Figure S1. Database content and selection criteria

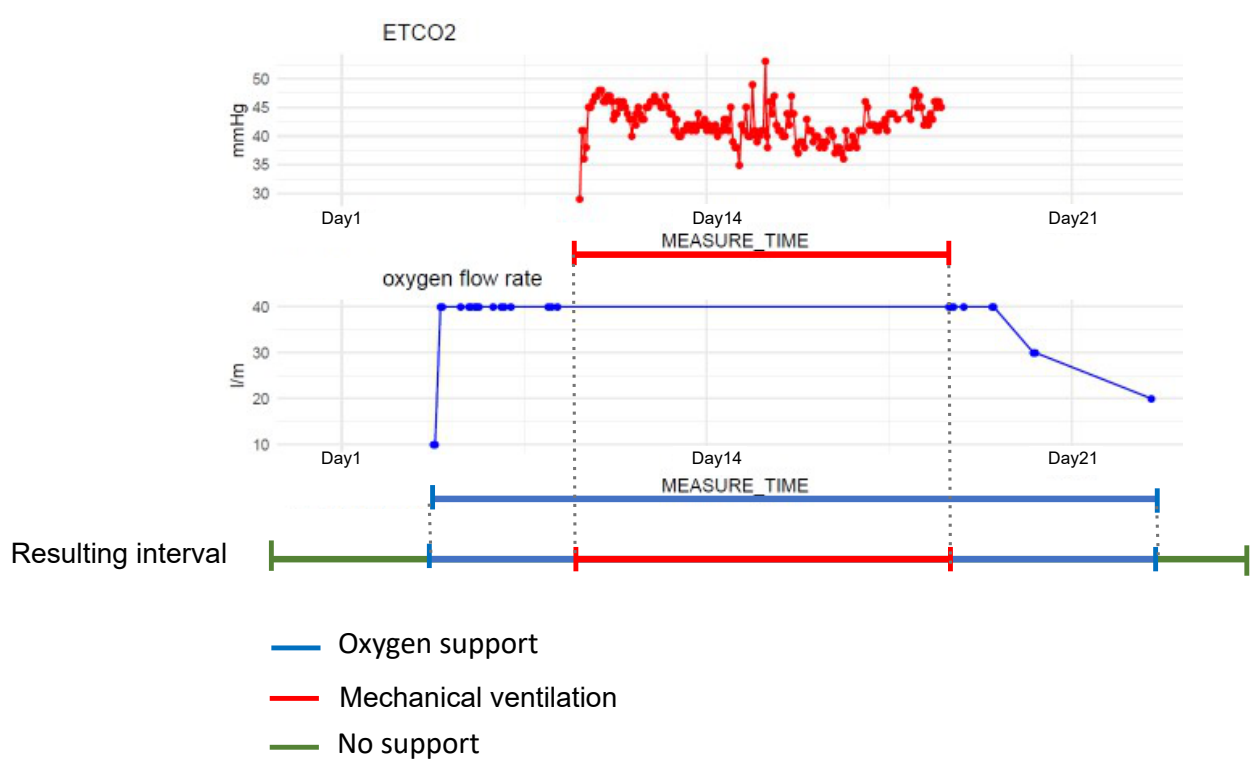

Figure S2. Definition of oxygen support and mechanical ventilation intervals. The first and the last time stamp are used from the oxygen flow rate and from the EtCO2 channel. No support is defined between the admission and the first information about support (or the last and the discharge) or if there is no support information, the whole monitoring is considered without support. 
medRxiv preprint doi: https://doi.org/10.1101/2021.09.26.21264135; this version posted November 8, 2021. The copyright holder for this preprint (which was not certified by peer review) is the author/funder, who has granted medRxiv a license to display the preprint in perpetuity.

\section{It is made available under a CC-BY-ND 4.0 International license .}

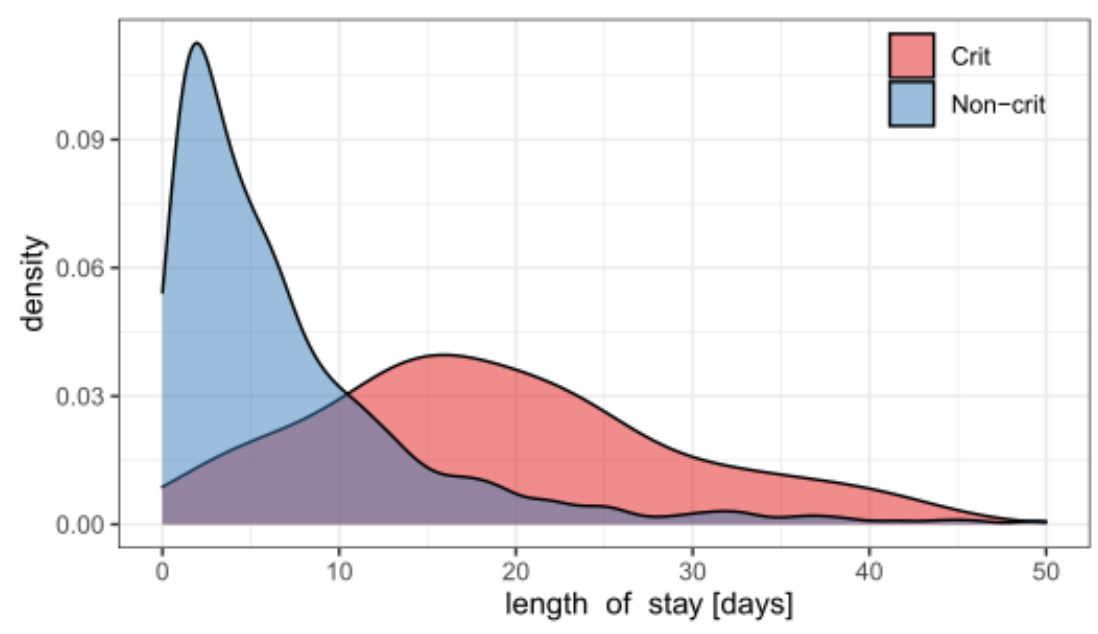

Figure S3. Distribution of length of stay for critical (red) and non-critical (blue) COVID-19 patients.
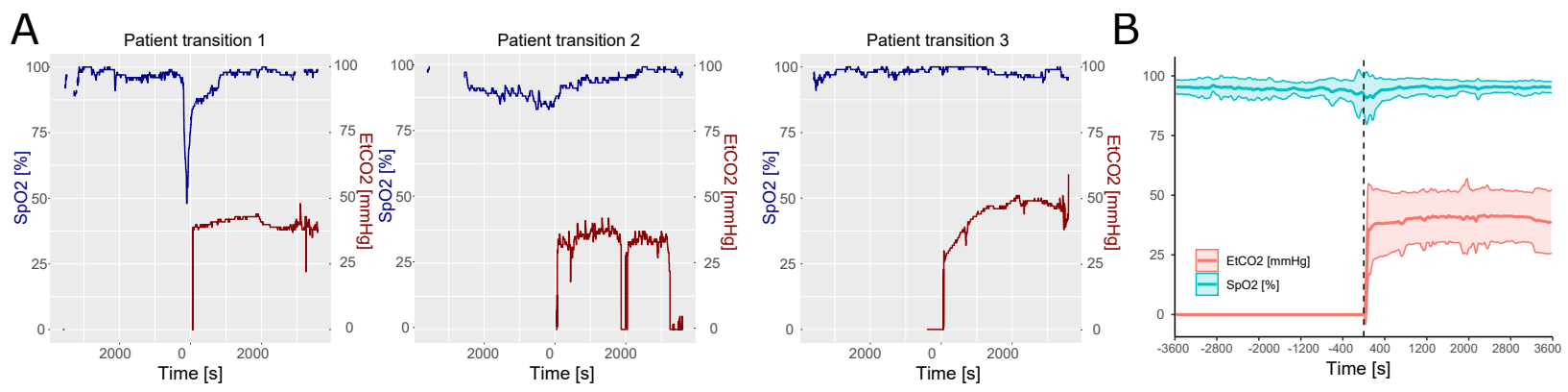

Figure S4. Effect of the ventilation on SpO2 signal at the initiation of the ventilation. A) Representative initiation of ventilation in three different patients. EtCO2 (red) and SpO2 (blue) signal were extracted using $2 \mathrm{~h}$ window centered on the ventilation initiation. $\mathrm{B}$ ) Average and standard deviation of EtCO2 and $\mathrm{SpO} 2$ for all the detected transitions. 
medRxiv preprint doi: https://doi.org/10.1101/2021.09.26.21264135; this version posted November 8, 2021. The copyright holder for this preprint (which was not certified by peer review) is the author/funder, who has granted medRxiv a license to display the preprint in perpetuity.

It is made available under a CC-BY-ND 4.0 International license.

A Oxygen support/no support Non-critical

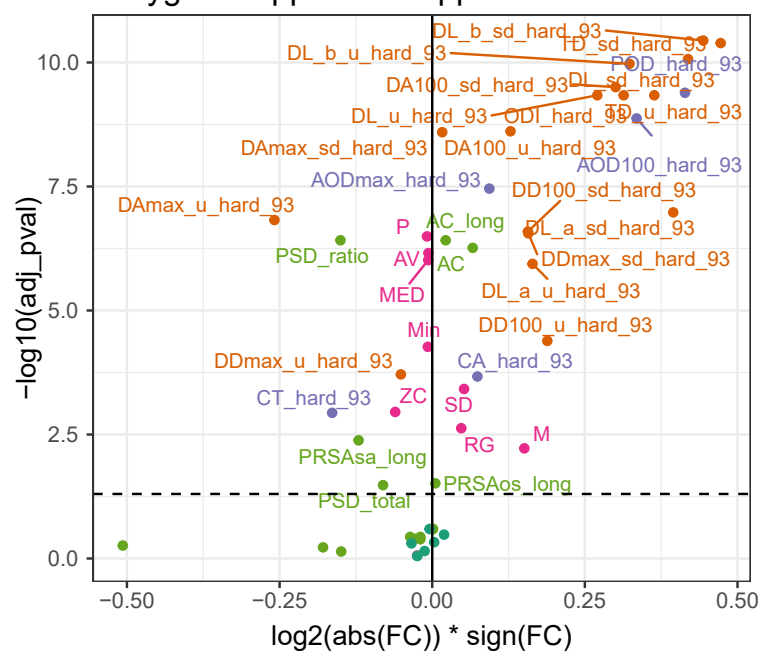

C Mechanical ventilation/no support critical

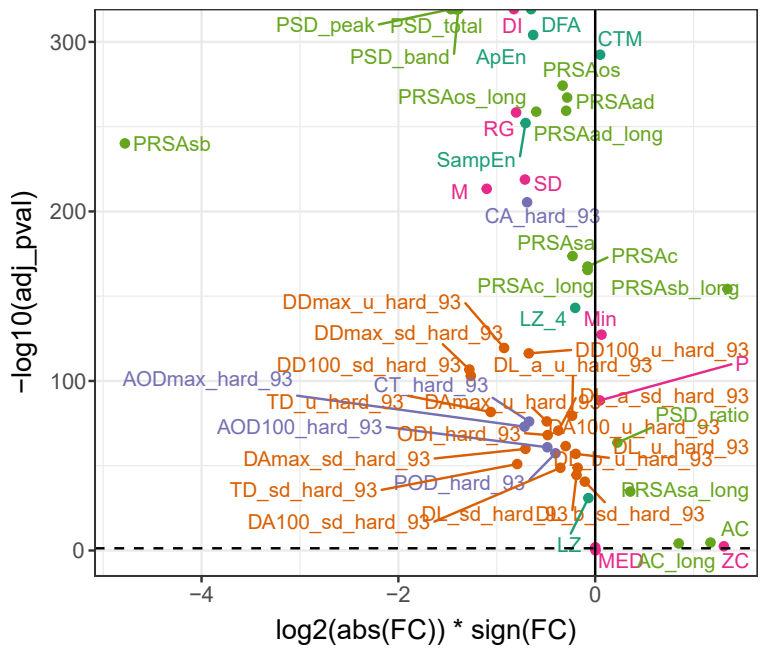

B

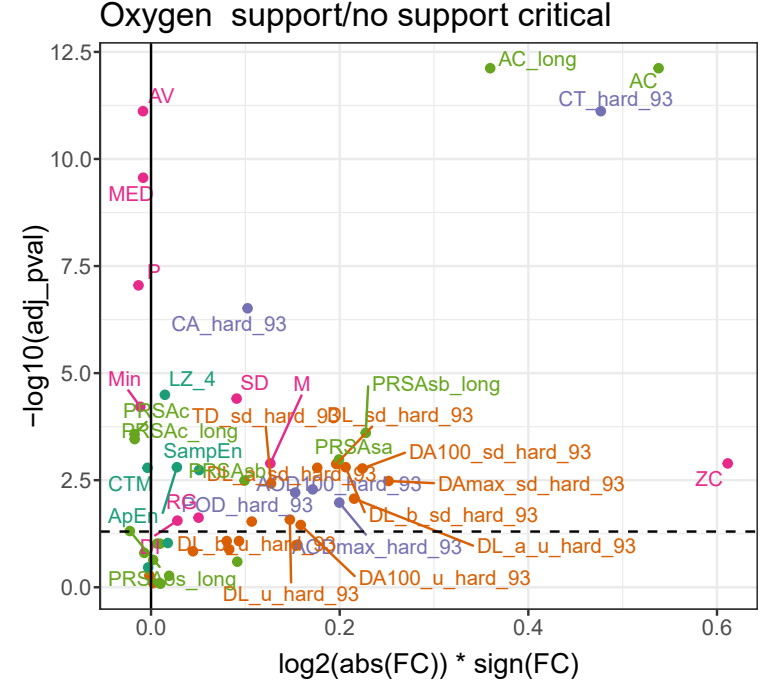

Figure S5. OBMs across the spectrum of disease severity and treatment support. A) Non-critical under oxygen compared to noncritical without support. B) Critic under oxygen compared to critical without support. C) Critic under mechanical ventilation compared to critical without support. OBMs definition are available in Table S3 
medRxiv preprint doi: https://doi.org/10.1101/2021.09.26.21264135; this version posted November 8, 2021. The copyright holder for this preprint (which was not certified by peer review) is the author/funder, who has granted medRxiv a license to display the preprint in perpetuity.

It is made available under a CC-BY-ND 4.0 International license.

A
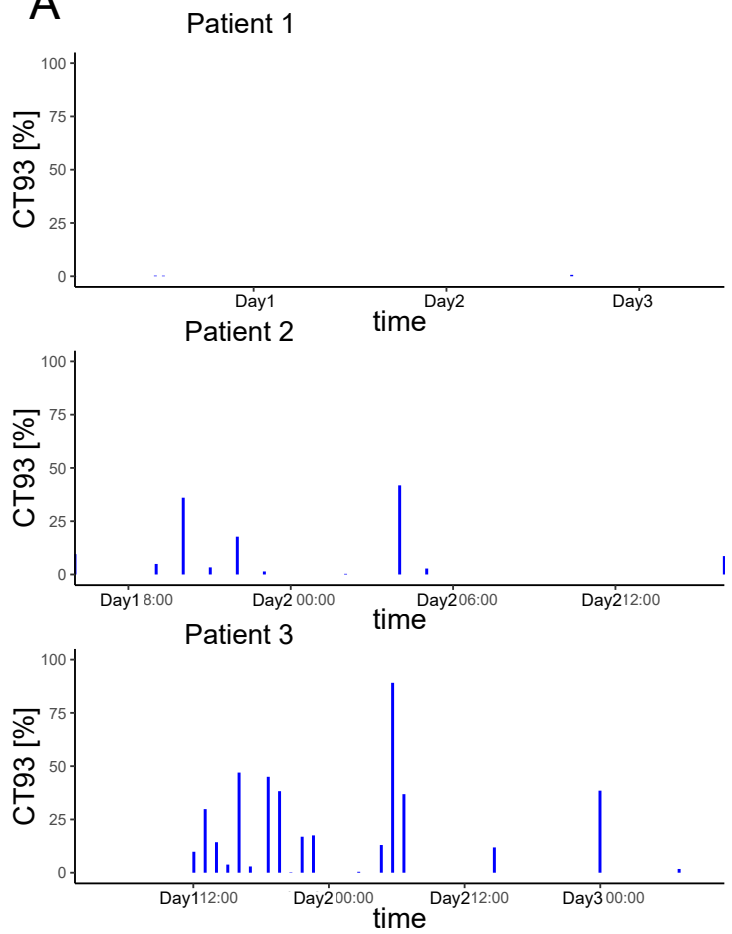

B
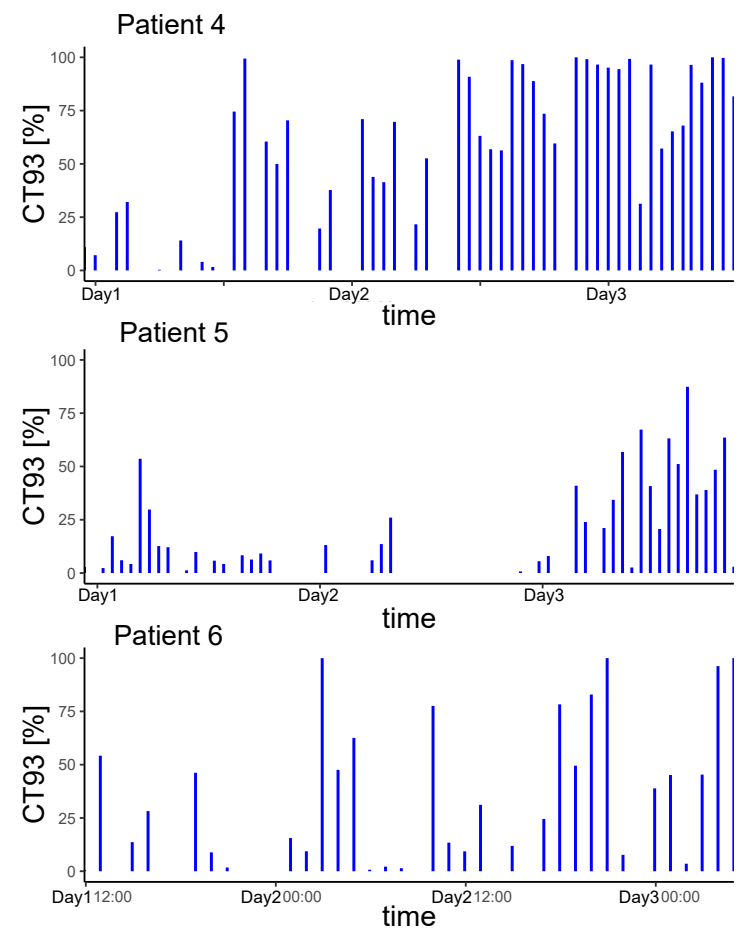

Figure S6. OBM CT93, defined as the percentage of time under the $93 \% \mathrm{SpO} 2$ threshold, extracted from $1 \mathrm{~h}$ windows for representative A) non-critical and B) critical patients without support. СT93 was the most discriminating biomarker between critical and non-critical group. 